\title{
Promotion Tournaments and Capital Rationing
}

\author{
Bing Han \\ McCombs School of Business, University of Texas at Austin
}

David Hirshleifer

Merage School of Business, University of California, Irvine

John C. Persons

Fisher College of Business, Ohio State University

\begin{abstract}
We analyze capital allocation in a conglomerate where divisional managers with uncertain abilities compete for promotion to CEO. A manager can sometimes gain by unobservably adding variance to divisional performance. Capital rationing can limit this distortion, increase productive efficiency, and allow the owner to make more accurate promotion decisions. Firms for which CEO talent is more important for firm performance are more likely to ration capital. A rationed manager is more likely to be promoted even though all managers are identical ex ante. When the tournament payoff is relatively small, offering an incentive wage can be more efficient than rationing capital; however, when tournament incentives are paramount, rationing is more efficient. (JEL G30, G31, G39)
\end{abstract}

Firms often seem to provide their divisions with less capital than would be needed to fund all positive-net present value projects, even though the corporation is free to raise additional capital at low transaction costs. This phenomenon, capital rationing, is a continuing puzzle. ${ }^{1}$ Some explanations have involved reputation effects, asymmetric information, empire building propensities, and intrafirm bargaining. ${ }^{2}$ In this article, we offer a new explanation for this behavior that does not rely on private information or on managers' inherent desire for large amounts of capital. Our explanation is based

We are grateful for helpful comments and suggestions from an anonymous referee, Major Coleman, Adolfo de Motta (WFA discussant), Denis Gromb, Rose Liao, Sonya Seongyeon Lim, Terrance Odean (the Editor), Christof Stahel, Karen Wruck, and seminar participants at Ohio State University and Hope College, and at the 2006 Western Finance Association meetings. Send correspondence to John Persons, Ohio State University, 2100 Neil Avenue, Columbus, OH 43210; telephone: (614)-292-4318; E-mail: jp@ cob.osu.edu.

${ }^{1}$ In a 1976 survey of large U.S. companies, Gitman and Forrester (1977) find that 52\% of respondents engaged in capital rationing. Mukherjee and Hingorani (1999) find 64\% of the respondents to a 1992 survey of the Fortune 500 firms operate in a capital rationing environment at least some of the time.

2 See, for example, Holmström and Ricart i Costa (1986); Harris and Raviv (1996); Thakor (1990); Stein (1997, 2002); Scharfstein and Stein (2000); and Rajan, Servaes, and Zingales (2000).

(C) The Author 2008. Published by Oxford University Press on behalf of The Society for Financial Studies. All rights reserved. For Permissions, please e-mail: journals.permissions@ oxfordjournals.org. doi: $10.1093 / \mathrm{rfs} / \mathrm{hhn} 085$

Advance Access publication October 2, 2008 
on the observation that the structure of internal labor markets resembles a tournament. $^{3}$

Owing to uncertainty about managerial talent, the owner learns about managerial ability by observing performance (as do the managers themselves). When divisional managers are competing to be promoted to the position of CEO, they consider how their actions affect the inferences made by the owner. Each manager seeks to increase the probability that he will be evaluated as the very best of the cohort, thus earning promotion. Because of the incentive to be in the upper tail of the talent distribution, managers add variance to the divisional outcomes if they can do so unobservably and without destroying too much value.

Because the owner knows the manager's objective and understands the opportunities to surreptitiously increase risk, he forms assessments accurately-the manager gains no advantage in equilibrium relative to a setting in which the manager has no discretion over project risk. When making inferences about managerial talent, the owner adjusts the outcomes to take account of his conjecture about the division's additional risk. Even so, it remains in the manager's private interest to play the game by adding excess variance. If he were to deviate from equilibrium by failing to do so, the owner would still assume he was increasing risk. The failure to increase risk would reduce the probability that the manager ends up with the highest inferred ability, thereby reducing his probability of promotion.

We assume that a manager increases variance by diverting some of the division's resources from their most efficient use to another, risk-increasing use. Such activity destroys part of the value of the division's projects. For a given amount of distortion, we assume that the value lost is greater for more profitable projects. We find that capital rationing, which limits managers to superior projects for which risk distortion is less attractive, can be beneficial.

We consider a model in which each of three divisions has two independent investment opportunities. ${ }^{4}$ Both projects have positive net present value (NPV). The more valuable project is labeled project $a$ and the less valuable one is project $b$. If each division is fully funded, then for some parameter values, the managers will engage in the variance distortion scheme described above. This impairs divisional performance, reducing the owner's wealth, because some of

\footnotetext{
3 For instance, see Lazear and Rosen (1981); Green and Stokey (1983); Rosen (1986); MacLeod and Malcolmsen (1988); and Bognanno (2001). Promotion can be an effective method to motivate workers. Lazear and Rosen (1981) show that the tournament compensation structure for risk-neutral workers produces the same incentive structure as does the optimal piece-rate contract, which pays workers the value of their products. If it is less costly to observe rank than an individual's level of output, then tournaments dominate piece rates.

4 The incentive among a set of ex ante symmetric managers to add variance occurs only when there are at least three managers (see Proposition 1). A manager facing multiple rivals must exceed an extreme value statistic, the maximum performance of the other competitors. This creates an advantage to having more extreme outcomes. In contrast, if there is only one rival, then higher variance neither helps nor hurts per se; if increasing the variance entails a reduction in mean, then this hurts the manager. However, even with only two players, adding variance can be attractive in a contest in which players are asymmetrically positioned (Aron and Lazear 1987).
} 
the resources of project $b$ are diverted from their best use to variance-increasing activities. ${ }^{5}$ In addition, variance distortion makes the owner's inference problem more difficult because the additional noise makes signals of manager talent less informative. This results in poorer decisions about which of the three managers to promote to CEO, which also reduces the owner's wealth.

One method of mitigating these problems is to provide one or more of the divisions with only enough capital to invest in one project. If distorting variance wastes more value when the project is more profitable, then it is more costly for the manager to divert resources from a superior project. When given only enough capital for the better project, the manager optimally distorts less. This provides the owner with two benefits: higher profits due to more efficient production, and fewer promotion mistakes (owing to better inferences about manager talent). The cost is that a positive-NPV investment opportunity, project $b$, is foregone. When the value of accurately assessing the talent of divisional managers is sufficiently large relative to the value of project $b$, rationing capital to at least one division is optimal. Furthermore, the owner understands that a rationed manager will add less risk, so the owner observes a more precise signal of that manager's ability. This makes the owner's posterior assessment of the manager's ability more sensitive to observed performance, increasing the chance that he wins top ranking. In consequence, the manager of a rationed division is more likely to win promotion, even though the managers are ex ante identical.

For most of the analysis, we follow the incomplete contracts approach of Grossman and Hart (1986) and Hart and Moore (1990) by assuming that the value created by the divisional manager is not contractible (e.g., because it cannot be verified by a court). However, to explore wages as an alternative avenue for influencing behavior, we also consider a setting where there is a binary variable correlated with divisional performance that can be used for contracting. If the correlation is sufficiently high and the CEO "prize" is small enough, the owner may choose to offer an incentive wage. But when the tournament prize is large, capital rationing is more effective. Since we are interested in situations where tournament incentives are paramount, we focus most of our attention on rationing rather than incentive wages.

Our basic model takes the structure of the firm (three divisions) as given; we then explore the implications of our approach for the optimal scope of the organization. An interesting trade-off arises from learning about the talent of the divisional managers. The advantage of a conglomerate is that an exceptionally talented CEO can create value in a broader domain. However, a conglomerate with many divisions induces very large distortions by managers, since a manager is much less likely to be rated best of ten candidates than best

\footnotetext{
5 Such activities could include spending time and firm resources on pure gambles, such as trading in derivative securities unrelated to the firm's business. But our setting also allows simply for project choices that are riskier but provide lower expected payoffs.
} 
of three candidates. The advantage of stand-alone divisions is that they avoid the variance distortion resulting from the CEO tournament.

The model focuses on the internal labor market, but we discuss possible extensions to include an external market for CEOs. Although distortions are absent from stand-alone divisions in our basic setting, when there are potential external candidates for CEO, a de facto tournament is in process. Therefore, excessive risk taking can occur even in focused firms, though presumably to a lesser extent, as promotion may occur through nontournament means. It also seems reasonable that better information about manager talent can be obtained inside the firm than externally. Both these factors illustrate potential efficiencies of conglomerates, since the conglomerate form admits the use of capital rationing to control risk taking. Whether a conglomerate or a focused structure is better depends on the importance of learning about managerial ability and the costs of rationing capital. Changes in these fundamental factors may lead to mergers, divestitures, spin-offs, and so on.

We also explain why it can be value-maximizing for the owner to announce that a subset of the contenders have the "inside track" for the CEO position. This is a common practice; a recent example is provided by the promotions of Stephen Crawford and Zoe Cruz to be co-presidents of Morgan Stanley, an event that precipitated the battle between dissidents and incumbent CEO Phillip Purcell (Craig and Smith 2004). In our model, narrowing the set of contenders can eliminate the incentives of both the managers who are left out of the running and the remaining contenders to add variance, thereby improving production efficiency and providing better information about their true talent. ${ }^{6}$

Previous articles examine capital allocation within the firm, and capital rationing in particular. Several such models rely on asymmetric information, empire-building preferences, or bargaining among divisions. ${ }^{7}$ Our article does not rely on these features and, in contrast to Stein $(1997,2002)$ and Scharfstein and Stein (2000), rationing is efficient in our model even when there are no impediments to raising external capital.

Much closer to our approach is the model of Holmström and Ricart i Costa (1986). They develop a model of capital allocation that is also based on career concerns and, as in our model, risk-taking behavior plays an important role. The optimal contract in their model provides downside protection to a risk-averse

\footnotetext{
6 The Morgan Stanley episode illustrates a danger of such a maneuver that is outside our model—talented managers who have been eliminated from the tournament may leave the firm.

7 In Antle and Eppen (1985), the manager has private information about production costs and can consume any excess capital, and the optimal rule involves rationing capital. In Harris and Raviv (1996), the manager reports his private information, and headquarters can audit the report to see if it is truthful. The managers in their model like more capital due to the private benefits they derive. They find that certain divisions should be rationed, while other divisions should be overfunded. Stein $(1997,2002)$ and Scharfstein and Stein (2000) develop models in which the incentives of both the divisions and headquarters are due to private benefits from controlling capital, and capital rationing arises within the firm only when external capital is also rationed. Rajan, Servaes, and Zingales (2000) offer a model of capital allocation in which the divisions bargain ex post over the surplus generated by their projects.
} 
manager. This protection can in equilibrium make the managers too eager to adopt projects. The owner therefore commits to a capital allocation rule that determines whether the managers' projects are funded. Capital is rationed in the sense that the optimal contract leaves some positive-NPV projects unfunded.

Our approach differs from that of Holmström and Ricart i Costa (1986) in several ways. Their managers have private information about the investment projects, and the managerial contract is designed to elicit this information. The managers in our model have no such private information. Risk aversion is crucial to their results; if the manager were risk neutral, first best would be achieved and there would be no rationing of capital. Risk aversion plays no role in our results, as managers in our model are risk neutral. Another fundamental difference is that managers in our model can alter the riskiness of the projects. Managers in their model do not affect the risk of available projects; rather they decide whether to invest. Of course, all of our results depend on the tournament structure of the internal labor market, which is absent from their model.

Milbourn, Shockley, and Thakor (1999) provide a model in which managers in a multistage promotion tournament become excessively averse to failure in their assigned tasks. Their article does not examine the issue of capital rationing. A key difference between their setting and ours is that their model has multiple positions into which the group of managers can be promoted, so that a manager can attain promotion simply by avoiding a failure that would distinguish him or her from other managers. Our focus is on the final promotion stage of high-level managers to a single CEO position, so that a manager needs to stand out as superior in order to obtain the promotion.

The article proceeds as follows. Section 1 presents the model. Section 2 examines how the existence of the promotion tournament affects risk-taking behavior by the division managers. Section 3 considers the use of incentive wages to influence managerial behavior, and Section 4 examines the optimal allocation of capital. Section 5 discusses possible extensions. Section 6 concludes.

\section{The Model}

\subsection{Structure}

There are $n=3$ divisional managers who are risk neutral and have uncertain talent $\theta_{i}$. The $\theta_{i}$ are independent and normal with mean zero and variance $\sigma_{\theta}^{2}$. This prior distribution is common to the owner and all the managersmanagers have no private information about their talent. At date 0 , the owner allocates capital $I$ to a manager, and the manager invests in his division's operations. There are two investment projects available, $a$ and $b$. Each project requires an investment of one unit of capital. The use of the physical capital is contractible, so the owner can direct the managers to invest in project $a$, 
project $b$, or both. ${ }^{8}$ Project $a$ generates a higher expected payoff than project $b, v_{a}>v_{b}>1$. For the time being, we assume that the owner allocates $I=2$ to each manager, so the manager invests in both projects. We later consider the optimality of rationing capital. The manager also chooses whether to add some excess variance to the project outcome; this will be explained shortly.

After the outcomes are observed for all the managers, the owner, who is also risk neutral, promotes one manager to be the new CEO. The manager's payoff for being promoted is a monetary "prize" $Z>0$, received from the firm. ${ }^{9} Z$ is not chosen by the owner, but is taken to be exogenous (e.g., determined by competition in the managerial labor market). For simplicity, the discount rate is taken to be zero.

The outcome of division $i$ 's operations is denoted $x_{i} ; x_{i}$ is observable but not contractible. Our motivation for assuming that $x_{i}$ is not contractible is the standard notion in the incomplete contracts literature that any measure used in a contract must be verifiable by the court. Given the nature of $x_{i}$, it would be impossible (or at least prohibitively costly) to verify. This is so because the outcome $x_{i}$ represents the value effect of all the actions taken by the manager while running the division. In addition to the current profitability of projects $a$ and $b$, this includes the anticipated cash flows from these projects that have yet to be realized. Beyond this, $x_{i}$ represents the effectiveness of the manager's strategic initiatives; the plans put into motion for future investment projects; his ability to recruit, motivate, and develop talented employees; his aptitude at managing important customer and supplier relationships; and the myriad other qualities that will determine future profitability. Taking $x_{i}$ to be noncontractible is reasonable because value creation involves not just the current period's cash flow, but also the change in the present value of future cash flows.

If the manager utilizes corporate resources efficiently, with no risk-altering distortions, the outcome is

$$
x_{i}=\theta_{i}+v_{a}+v_{b}+u_{i}-2,
$$

where the $u_{i}$ are independent mean-zero normals with variance $\sigma_{u}^{2}$. We define $\sigma_{\theta+u}^{2}=\sigma_{\theta}^{2}+\sigma_{u}^{2}$. Thus, the unexpected outcome, $x_{i}-v_{a}-v_{b}+2$, provides an unbiased signal of the manager's talent $\theta_{i}$. In addition to the value created by the divisions' date-0 production $\sum_{i} x_{i}$, additional value is created for the owner by the CEO in the next period. The date-1 payoff for the owner is assumed to be linear in the talent $\theta$ of the manager who is promoted to CEO, $M \theta-Z$.

${ }^{8}$ All of our results continue to hold when project choice is unobservable. The owner desires that the manager invest in both projects when given two units of capital and in project $a$ when given only one unit of capital. If this is the behavior anticipated by the owner, one can show that a manager making unobservable investments would choose to follow that policy.

${ }^{9}$ In reality, part of the benefit of being promoted to CEO consists of nonpecuniary benefits, such as satisfaction from a more challenging job, prestige, or more pleasant working conditions, and of monetary benefits that do not come from the firm, such as opportunities to serve on the boards of other firms or gifts from suppliers. Including nonpecuniary benefits in $Z$ would have no qualitative effect on our results. 
We refer to $M>1$ as a span-of-control parameter; it is greater than 1 because promotion magnifies the impact of the manager's talent on firm value. If the CEO has at least as much effect on each division's performance as the divisional manager, then $M \geq 3$. Of course, the CEO may also create value that is not division-specific.

The division managers choose whether to distort the use of corporate resources to add some excess variance to the outcome $x$. Manager $i$ can add noise $s_{i} \epsilon_{i}$ to the outcome, where $s_{i} \geq 0$, and where the $\epsilon_{i}$ are standard normal, mutually independent, and independent of the $\theta_{i}$ and $u_{i}$. This choice is unobservable but, in equilibrium, the owner (correctly) conjectures the choices of the managers. Adding risk $s \epsilon$ increases the variance of $x$ from $\sigma_{\theta+u}^{2}$ to $\sigma^{2}=\sigma_{\theta+u}^{2}+s^{2}$; it is sometimes easier to think of the manager choosing $\sigma$ rather than choosing $s$.

A decision to add variance to $x$ requires that the manager distort the use of the division's resources, thus reducing value. The assumption that variance can be manipulated at the expense of mean performance is similar to that made by Cadenillas, Cvitanic, and Zapatero (2005) and by Bolton, Scheinkman, and Xiong (2006) in related contexts. ${ }^{10}$ For example, a manager may shift resources excessively from existing production to risky R\&D initiatives, or may undertake organizational changes whose benefits are questionable and whose outcomes are highly uncertain. Investment in marketable risky securities, such as derivatives, can be used to increase volatility; if corporate resources including executive time and attention are diverted to pursuing such strategies, they can decrease ex ante value. Each unit increase in variance from resource misallocation is assumed to destroy a fixed fraction $\delta$ of the project's value. Because of this, a manager who is investing in both projects will choose to distort project $b$ rather than project $a$. The value lost is proportional to the excess variance and to the investment's value:

$$
\delta s^{2} v_{b}=\delta\left(\sigma^{2}-\sigma_{\theta+u}^{2}\right) v_{b},
$$

where $\delta$ is a positive parameter. ${ }^{11}$ Therefore, conditional on manager $i$ 's strategy, the division's outcome is

$$
x_{i}=\theta_{i}+v_{a}+v_{b}\left(1-\delta s_{i}^{2}\right)+u_{i}+s_{i} \epsilon_{i}-2 .
$$

10 We could also permit managers to distort production so as to reduce variance. In our model with identical managers, they would never pursue such opportunities. If the managers were not identical ex ante, one could not rule out risk-reducing distortions. Risk reduction can certainly occur in other settings, such as models with risk-averse managers where losers of the promotion contest (potentially) earn some future rents (Holmström and Ricart i Costa 1986), or where owners seek to make profitability a more accurate indicator of managerial effort (e.g., Hirshleifer and Suh 1992).

11 To motivate this formulation, consider an investment project that has value $v(1-d)$ if there is no labor input. Each of the division's 10 workers has marginal product $d v / 10$ if used productively, so the maximum project value is $v$. Alternatively, the manager can send any or all workers to the racetrack to bet $\$ k$ on an even-odds horse. The odds are actuarially fair. If the manager chooses to send $n$ workers to the track, this increases the variance of divisional profits by $s^{2}=n k^{2}$. Defining $\delta=d /\left(10 k^{2}\right)$, the value of the project is $v(1-n d / 10)=v\left(1-s^{2} \delta\right)$, as assumed in the text. 
If $s_{i}>0, x_{i}-v_{a}-v_{b}\left(1-\delta s_{i}^{2}\right)+2$ provides an unbiased but noisier signal of $\theta_{i}$.

\subsection{The promotion tournament}

After managers make their choices at date 0, the random variables are realized, and the owner observes the $x_{i}$. Based on this, he updates each prior mean $E\left[\theta_{i}\right]=0$ to a posterior mean, $E_{1}\left[\theta_{i}\right]=\bar{\theta}_{1 i}$. Given our assumptions, the ex ante distribution of the posterior mean $\bar{\theta}_{1 i}$ is normal, as is the posterior distribution of $\theta_{i}$. The variance of $\bar{\theta}_{1 i}$ will be greatest if the managers' equilibrium strategies add no noise; then the division's performance $x_{i}$ is maximally informative about manager $i$ 's ability, inducing the greatest updating by the owner.

Each of the risk-neutral managers would like to generate the highest posterior mean in order to win the promotion contest. With more than two contestants, a manager can increase his chance of winning if he can increase the variance of his posterior mean without reducing the expected posterior mean. This makes it tempting to conclude that equilibrium must have each $s_{i}=0$, since this would yield the highest possible equilibrium variance of $\bar{\theta}_{1 i}$ (and would maximize $E\left[x_{i}\right]$ ) if the owner observed the manager's action. However, the owner cannot observe the manager's choice of variance. If the owner anticipates an equilibrium choice $\hat{s}_{i}$, his posterior mean assessment is

$$
\bar{\theta}_{1 i}=\left(\frac{\sigma_{\theta}^{2}}{\sigma_{\theta+u}^{2}+\hat{s}_{i}^{2}}\right)\left[x_{i}-v_{a}-v_{b}\left(1-\delta \hat{s}_{i}^{2}\right)+2\right] .
$$

Taking the owner's equilibrium conjecture as given, managers have an incentive to increase the variance of $x$ if doing so does not reduce the mean of $x$ too much, even though this will end up reducing the variance of $\bar{\theta}_{1}$ in equilibrium. To see this, note that although the owner believes $x_{i}$ is distributed as

$$
x_{i} \sim \theta_{i}+v_{a}+v_{b}\left(1-\delta \hat{s}_{i}^{2}\right)+u_{i}+\hat{s}_{i} \epsilon_{i}-2,
$$

manager $i$ knows his choice $s_{i}$ and therefore knows that the true distribution of $x_{i}$ is

$$
x_{i} \sim \theta_{i}+v_{a}+v_{b}\left(1-\delta s_{i}^{2}\right)+u_{i}+s_{i} \epsilon_{i}-2 .
$$

Thus, the manager knows that the owner's posterior belief is really

$$
\begin{aligned}
\bar{\theta}_{1 i} & =\left(\frac{\sigma_{\theta}^{2}}{\sigma_{\theta+u}^{2}+\hat{s}_{i}^{2}}\right)\left[x_{i}-v_{a}-v_{b}\left(1-\delta \hat{s}_{i}^{2}\right)+2\right] \\
& =\left(\frac{\sigma_{\theta}^{2}}{\sigma_{\theta+u}^{2}+\hat{s}_{i}^{2}}\right)\left[\theta_{i}-\left(s_{i}^{2}-\hat{s}_{i}^{2}\right) \delta v_{b}+u_{i}+s_{i} \epsilon_{i}\right] .
\end{aligned}
$$


A marginal increase in $s_{i}^{2}$ increases the (true) variance of $\bar{\theta}_{i}$, but at the cost of reducing its expected value at rate $\delta v_{b}$. The owner's expectations affect the manager's optimal choice of risk by determining how the posterior mean will be calculated. In a perfect Bayesian equilibrium, the owner is not fooled-his conjecture $\hat{s}_{i}$ coincides with the manager's optimal choice of $s_{i}$. Therefore, in equilibrium, the posterior mean is

$$
\bar{\theta}_{1 i}=\left(\frac{\sigma_{\theta}^{2}}{\sigma_{\theta+u}^{2}+\hat{s}_{i}^{2}}\right)\left(\theta_{i}+u_{i}+\hat{s}_{i} \epsilon_{i}\right) \text {, }
$$

which is distributed normally with zero mean and with standard deviation $\sigma_{\theta}^{2} / \sqrt{\sigma_{\theta+u}^{2}+\hat{s}_{i}^{2}}$

\subsection{Wages}

Although a division's degree of success is not contractible (assumed for the reasons discussed earlier), we suppose that there is a contractible variable correlated with $x$. This gives the owner the opportunity to influence managerial risk taking through compensation, which might be an efficient way to reduce the distortions caused by the promotion tournament.

Specifically, we assume there is a binary contracting variable $y$ that indicates whether the manager's division is doing better than expected (a "success," $y=1$ ) or worse than expected (a "failure," $y=0$ ). This provides a simple and tractable way to investigate wage incentives. With probability $\alpha$, the variable $y$ reveals whether $x$ is above or below the mean $E[x]=v_{a}+v_{b}\left(1-\delta v_{b} \hat{s}^{2}\right)-2$. With probability $1-\alpha, y$ is chosen randomly from $\{0,1\}$, with equal probabilities. If $\alpha=0, x$ and $y$ are uncorrelated; higher $\alpha$ means higher correlation between $x$ and $y$. Thus, $y$ provides a more informative indicator of the manager's effectiveness when $\alpha$ is high. The chance of a good signal of divisional performance is

$$
\begin{aligned}
\operatorname{Pr}\left[y_{i}=1\right]=E\left[y_{i}\right] & =(1-\alpha)(1 / 2)+\alpha \operatorname{Pr}\left[x_{i}>E\left[x_{i} \mid \hat{s}_{i}\right]\right] \\
& =(1-\alpha)(1 / 2)+\alpha \operatorname{Pr}\left[\theta_{i}+u_{i}+s_{i} \epsilon_{i}-\delta v_{b}\left(s_{i}^{2}-\hat{s}_{i}^{2}\right)>0\right] .
\end{aligned}
$$

In equilibrium, $y=0$ and $y=1$ are equally likely because $s=\hat{s}$ and the distribution of $x$ is symmetric.

When $\alpha$ is positive, making a wage payment contingent on the contracting variable $y$ can influence risk taking because the managers care about expected wages, as well as the probability of winning the promotion prize $Z$. It is easy to see that the owner's optimal wage schedule would make no payment for a failure, $y=0$; we use $w$ to denote the wage paid for a success, $y=1$. In Section 3, we investigate the use of incentive wages to influence behavior. In the sections following that, we assume $\alpha=0$ and concentrate on capital allocation 
as a control method. (When $\alpha=0$, wages do not influence managerial choices, so the owner optimally sets $w=0$.)

\subsection{Payoffs and equilibrium}

Managers care about their expected wages and the probability of being promoted to CEO. Let $i^{*} \in\{1,2,3\}$ be a random variable that denotes the manager who is promoted, $i^{*}=\arg \max _{i} \bar{\theta}_{1 i}$. (We ignore the zero-probability event of a tie.) Each manager, taking the choices of other managers as given, chooses $s_{i}$ to maximize:

$$
w \operatorname{Pr}\left[y_{i}=1\right]+Z \operatorname{Pr}\left[i^{*}=i\right]=w E\left[y_{i}\right]+Z \operatorname{Pr}\left[\bar{\theta}_{1 i}>\max _{j \neq i} \bar{\theta}_{1 j}\right] .
$$

Let $V_{0}=\sum_{i} E\left[x_{i}-w y_{i}\right]$ denote the expected value created by the divisions, and let $V_{1}=M E\left[\theta_{i^{*}}\right]-Z$ be the expected value creation by the promoted CEO. The owner wishes to maximize the total value created:

$$
V_{0}+V_{1}=\sum_{i} E\left[x_{i}-w y_{i}\right]+M E\left[\theta_{i^{*}}\right]-Z
$$

Equilibrium requires that manager choices be optimal, owner inferences be rational, and the owner's wage policy and capital allocation be optimal.

Definition 1. (Equilibrium) A set $\left\{s_{i}, G_{i}, I_{i}, w\right\}$ consisting of the managers' choices $s_{i}$, the owner's inference rules $G_{i}$, and the owner's capital allocation $I_{i}$, and incentive wage $w$ is an equilibrium if it satisfies the following conditions.

1. Each manager's choice $s_{i}$ maximizes his expected payoff $w E\left[y_{i}\right]+$ $Z \operatorname{Pr}\left[i^{*}=i\right]$, taking as given the owner's inference rules and the strategies of the other managers.

2. The owner's inference rules are consistent with Bayes' rule when managers follow their equilibrium strategies, i.e., $G_{i}\left(\hat{\theta} \mid x_{i}, I_{i}\right)=\operatorname{Pr}\left[\theta_{i} \leq\right.$ $\left.\hat{\theta} \mid x_{i}, I_{i}, s_{i}\right]$ for each $i$.

3. The owner's capital allocation and incentive wage $\left\{I_{i}, w\right\}$ maximize total value $V_{0}+V_{1}$.

We concentrate on equilibria that are symmetric in that managers who are allocated the same amount of capital choose identical strategies. In such equilibria, the owner's expectations are identical for those divisions.

The ideal outcome for the owner occurs when the managers refrain from adding noise without any capital restrictions or wage inducements. The owner provides a full allocation of capital to each division, maximizing $V_{0}$. In addition, the owner gets signals of $\theta_{i}$ that are as informative as possible, so he can 
minimize the number of promotion errors $-V_{1}$ is as large as it can be. With the best signals of managerial ability, the average talent of the new $\mathrm{CEO}$ becomes

$$
E\left[\theta_{i^{*}}\right]=\frac{3 \sigma_{\theta}^{2}}{2 \sqrt{\pi} \sigma_{\theta+u}}
$$

using the distribution of the first order statistic. ${ }^{12}$ Hence, under the first-best outcome ${ }^{13}$ the firm's value to the owner is

$$
V_{0}+V_{1}=3\left(v_{a}+v_{b}-2\right)+\frac{3 M \sigma_{\theta}^{2}}{2 \sqrt{\pi} \sigma_{\theta+u}}-Z
$$

We have assumed that there are three divisional managers. Suppose for a moment that there are only two. Our first result shows that the promotion tournament produces no distortions when only two managers compete-the owner can forgo wage payments and provide full capital allocations because choosing $s=0$ is a dominant strategy for the managers. In this situation, adding variance would only reduce the probability of promotion because the loss of $\delta v_{b} s_{i}^{2}$ would reduce the average $\bar{\theta}_{1 i}$.

Proposition 1. If there are only two managers, the unique equilibrium outcome has full capital allocations, no wage payments, and no excess variance $\left(I_{i}=2, w=0\right.$, and $s_{i}=0$ for all $\left.i\right)$, so first best is achieved.

Proof. Omitted.

To see that setting $s_{i}=0$ is a dominant strategy, first notice that in equilibrium (where the other manager sets $s_{j}=0$ ), manager $i$ gets a $50 \%$ chance of winning by choosing $s_{i}=0$. Any $s_{i}>0$ would produce a lower chance of promotion because the loss of $\delta v_{b} s_{i}^{2}$ would reduce the average $\bar{\theta}_{1 i}$. With only two contestants, a lower average $\bar{\theta}_{1 i}$ means the probability of winning is less than $50 \%$, regardless of the variances of $\bar{\theta}_{1 i}$ and $\bar{\theta}_{1 j}$.

12 For each manager, the posterior mean $\bar{\theta}_{1 i}$ is an unbiased estimate of the manager's talent, so $\max _{i} \bar{\theta}_{1 i}$ is an unbiased estimate of the talent of the new CEO, $\theta_{i} *$. For any equilibrium in which the managers follow identical strategies, each $\bar{\theta}_{1 i}$ has the same distribution, so the probability that the maximum is less than $\theta$ is $F^{3}(\theta)$, where $F$ is the cumulative distribution function of $\bar{\theta}_{1 i}$. Since each $\bar{\theta}_{1 i}$ is a mean-zero normal, the density of $\max _{i} \bar{\theta}_{1 i}$ is

$$
3 f(\bar{\theta}) F^{2}(\bar{\theta})=3 \phi(\gamma) \Phi^{2}(\gamma) / \sigma\left(\bar{\theta}_{1 i}\right),
$$

where $\gamma=\bar{\theta}_{1 i} / \sigma\left(\bar{\theta}_{1 i}\right)$ is standard normal, $\phi$ is the standard normal density, and $\Phi$ is the standard normal distribution function. Therefore, the average talent of the new CEO is

$$
E\left[\theta_{i^{*}}\right]=\int_{-\infty}^{\infty} 3 \theta f(\theta) F^{2}(\theta) \mathrm{d} \theta=3 \sigma\left(\bar{\theta}_{1 i}\right) \int_{-\infty}^{\infty} \gamma \phi(\gamma) \Phi^{2}(\gamma) \mathrm{d} \gamma=3 \sigma\left(\bar{\theta}_{1 i}\right) /(2 \sqrt{\pi}),
$$

where $\sigma\left(\bar{\theta}_{1 i}\right)=\sigma_{\theta}^{2} / \sqrt{\sigma_{\theta+u}^{2}+\hat{s}_{i}^{2}}$ by (3). Substituting into (6) using $\hat{s}_{i}=0$ gives (5).

13 We use the term first best to denote the best possible outcome for the owner of the firm. Since $w$ is a transfer, a wage contract that induces the managers to set $s=0$ would also achieve social efficiency, but at greater cost to the owner. 
On the other hand, if manager $j$ does add variance, then setting $s_{i}=0$ still maximizes the manager's chance of winning (with promotion probability higher than 50\%). Since the owner anticipates the same behavior from the two managers, manager $i$ would produce higher average $\bar{\theta}_{1 i}$ if $s_{i}$ is less than $s_{j}$; given this, the highest possible mean and lowest possible variance will maximize his promotion probability. Setting $s_{i}=0$ achieves both goals.

Since it is a dominant strategy to add no excess variance, the only equilibrium has $s_{1}=s_{2}=0$. Each manager has a $50 \%$ chance of winning promotion, and the owner's wealth is as high as it can possibly be. ${ }^{14}$

\section{Tournament Incentives and Risk Taking}

In this section, we examine how the tournament affects the operating/risktaking choices of managers, absent any wage incentives or capital rationing. That is, the owner makes a full capital allocation $I=2$ to each division, and the wage $w$ is zero.

Posit an equilibrium in which the owner expects managers to add variance $\hat{s}^{2}$, and define $\hat{\sigma}^{2}=\sigma_{\theta+u}^{2}+\hat{s}^{2}$ to be the equilibrium variance of $x$. We can simplify the analysis somewhat because the owner anticipates identical behavior from the managers; this implies that the manager with the highest realization $x_{i}$ will also be the one with the highest posterior mean assessment $\bar{\theta}_{1 i}$ [see (2)]. The equilibrium strategy generates $x$ with mean $v_{a}+v_{b}\left(1-\delta \hat{s}^{2}\right)-2$ and variance $\hat{\sigma}^{2}$. Consider the decision facing an individual manager $i$, taking the choices $\hat{s}_{j}$ of the other two managers as given. Suppose manager $i$ chooses noise $s_{i}^{2}$ and thus total variance $\sigma^{2}=\sigma_{\theta+u}^{2}+s^{2}$. The difference between his mean and the others' is $\delta v_{b}\left(\hat{\sigma}^{2}-\sigma^{2}\right)$, and the difference in variances is $\sigma^{2}-\hat{\sigma}^{2}$. That is, if $\sigma>\hat{\sigma}$, manager $i$ 's mean is lower and variance is higher.

The manager's goal is to maximize the probability of promotion, which we denote $W$. The manager wins if $x_{i}$ is greater than the other two $x_{j}$. For either $j$, the distribution of $x_{i}-x_{j}$ is the distribution of

$$
\sigma \gamma_{i}-\delta v_{b}\left(\sigma^{2}-\hat{\sigma}^{2}\right)-\hat{\sigma} \gamma_{j}
$$

where $\gamma_{i}$ and $\gamma_{j}$ are independent standard normals. Therefore, manager $i$ wins if

$$
\gamma_{i}>\max _{j \neq i}\left\{\frac{\hat{\sigma}}{\sigma} \gamma_{j}+\delta v_{b}\left(\sigma-\hat{\sigma}^{2} / \sigma\right)\right\}=\delta v_{b}\left(\sigma-\hat{\sigma}^{2} / \sigma\right)+\frac{\hat{\sigma}}{\sigma} \max _{j \neq i} \gamma_{j} .
$$

14 One can easily extend this intuition to promotion contests at lower levels in the organization. Suppose there are $N$ managers at a given level who are competing for the prize of being promoted to the next level, in a setting like the one we model. If fewer than half the managers will be promoted, then their incentives are to unobservably add variance, even if it destroys value. If more than half the managers will be promoted to the next level, then the incentives are reversed. If they can do so unobservably, the managers will destroy value by setting variance inefficiently low. 
Since the density of $\max _{j \neq i} \gamma_{j}$ is $2 \Phi(\gamma) \phi(\gamma)$, manager $i$ chooses $\sigma$ to maximize the probability of winning:

$$
W=2 \int_{-\infty}^{\infty} \Phi(\gamma) \phi(\gamma)\left\{1-\Phi\left(\delta v_{b}\left[\sigma-\hat{\sigma}^{2} / \sigma\right]+\gamma \hat{\sigma} / \sigma\right)\right\} \mathrm{d} \gamma
$$

which has derivative

$$
\begin{aligned}
\frac{\partial W}{\partial \sigma}= & \frac{2 \hat{\sigma}}{\sigma^{2}} \int_{-\infty}^{\infty} \gamma \Phi(\gamma) \phi(\gamma) \phi\left(\delta v_{b}\left[\sigma-\hat{\sigma}^{2} / \sigma\right]+\gamma \hat{\sigma} / \sigma\right) \mathrm{d} \gamma \\
& -2 \delta v_{b}\left(1+\hat{\sigma}^{2} / \sigma^{2}\right) \int_{-\infty}^{\infty} \Phi(\gamma) \phi(\gamma) \phi\left(\delta v_{b}\left[\sigma-\hat{\sigma}^{2} / \sigma\right]+\gamma \hat{\sigma} / \sigma\right) \mathrm{d} \gamma .
\end{aligned}
$$

The first term in (8) is the increased likelihood of promotion due to the higher variance of $x$ and the second term is the decreased likelihood of promotion due to the lower mean of $x$.

Proposition 2 states that first best is achievable if $\delta, v_{b}, \sigma_{\theta}$, or $\sigma_{u}$ is large enough. Large $\delta$ and $v_{b}$ make it costly to add variance because doing so causes a large reduction in the expected outcome. Large $\sigma_{\theta}$ and $\sigma_{u}$ reduce the marginal benefit of the extra variance on the probability of winning promotion.

Proposition 2. If $\delta v_{b} \sigma_{\theta+u} \geq 1 /(2 \sqrt{3 \pi})$, then the owner can achieve first best by setting $w=0$ and $I_{i} \equiv 2$. Managers with full capital allocations add no excess variance when the owner expects each to choose $s_{i}=0$.

Proof. See the Appendix.

When $\delta v_{b} \sigma_{\theta+u}$ is large enough, the promotion tournament induces no misallocation of resources, so there is no problem to be resolved. Therefore, for the rest of the article, we assume that $\delta v_{b} \sigma_{\theta+u}$ is sufficiently small so that managers will inflate risk, absent countervailing measures.

Standing Assumption 1. First best cannot be achieved: $\delta v_{b} \sigma_{\theta+u}<$ $1 /(2 \sqrt{3 \pi})$.

When $\delta v_{b} \sigma_{\theta+u}$ is relatively small, an owner who expects no excess variance (he anticipates $\hat{\sigma}=\sigma_{\theta+u}$ ) will be surprised, because the optimal response of each manager is then to inflate risk. Figure 1 illustrates this for a particular example that has $\sigma_{\theta+u}=0.5$. In a proposed equilibrium with no excess variance $(\hat{\sigma}=0.5)$, a manager would choose to add risk until $\sigma \approx 1.09$, confounding the owner's expectations.

The next proposition describes the unique symmetric equilibrium in the managers' subgame under our standing assumption that first best is infeasible. 


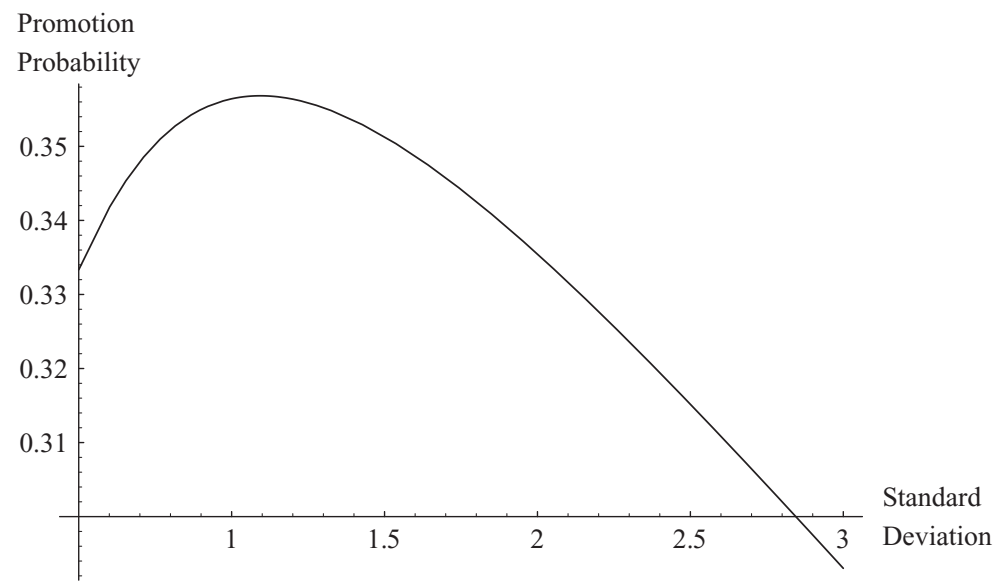

Figure 1

Manager's optimization if owner expects no excess variance

The figure plots the manager's probability of winning the promotion tournament, $W$, as a function of his choice $\sigma$, assuming that the owner anticipates no excess variance $\left(\hat{\sigma}=\sigma_{\theta+u}\right)$ and that the other managers are adding no excess variance. It is in the manager's interest to add variance, raising $\sigma$ to 1.09 , confounding the owner's expectations. The parameters for this example are $\sigma_{\theta}^{2}=\sigma_{u}^{2}=\delta=1 / 8$ and $v_{b}=5 / 4$.

Proposition 3. Suppose the managers receive full capital allocations $(I=2)$ and no wages $(w=0)$. The equilibrium of the managers' subgame has $\sigma=$ $1 /\left(2 \sqrt{3 \pi} \delta v_{b}\right)$ for each division. This is the unique symmetric equilibrium. The excess variance $s^{2}$ is decreasing in $\delta, v_{b}$, $\sigma_{\theta}$, and $\sigma_{u}$.

Proof. See the Appendix.

The most interesting of the comparative statistics in Proposition 3 is for $\sigma_{\theta}$, the dispersion in managerial talent. The distortions induced by the tournament are most severe when the managers are likely to be very similar ( $\sigma_{\theta}$ is small). Managers distort very aggressively when they are in a "tight race" because that is when some extra variance might well change the ranking — rank changes will seldom happen if the managers are likely disparate in ability.

Although it is rational for each manager to add variance to $x$, no advantage is gained in equilibrium - each manager has a $1 / 3$ chance of being promoted. But the manager must follow the equilibrium strategy of distorting variance to avoid having a lower probability of success than the other contestants. The promotion tournament creates inefficiency because managers can add noise unobservably. The managers would lose nothing, and the owner would benefit, if they could jointly commit to choosing $s=0$. However, if such an agreement were in place, each manager would have the incentive to break the agreement to increase his promotion probability (as shown in Figure 1), and the unobservability of $s$ would allow him to do so.

The excess variance hurts the owner in two ways. First, it directly reduces date- 0 value creation, $V_{0}$, by $3 s^{2} \delta v_{b}$. Substituting the equilibrium $s^{2}$ from 
Proposition 3 , the loss of initial value $V_{0}$ due to distorted production is

$$
\sum_{i}\left\{1 /\left(12 \pi \delta v_{b}\right)-\sigma_{\theta+u}^{2} \delta v_{b}\right\}=1 /\left(4 \pi \delta v_{b}\right)-3 \sigma_{\theta+u}^{2} \delta v_{b}
$$

(which is positive by Standing Assumption 1). Second, it reduces future value creation by the new CEO, $V_{1}$, because promotion decisions are less efficient. The noise added to the outcomes increases the likelihood that an inferior manager will be promoted to CEO. Footnote 12 shows that the average talent of the new CEO is proportional to the standard deviation of the posterior mean, $\sigma\left(\bar{\theta}_{1 i}\right)=\sigma_{\theta}^{2} / \sigma$. The noise added by the managers makes $\bar{\theta}_{1 i}$ less sensitive to the outcome $x_{i}$, reducing its standard deviation and thereby reducing $V_{1}$. Applying Equation (6) using the equilibrium $\sigma$ from Proposition 3, the value lost due to inferior promotion decisions is

$$
M \frac{3}{2 \sqrt{\pi}}\left(\frac{\sigma_{\theta}^{2}}{\sigma_{\theta+u}}-\sigma_{\theta}^{2}\left(2 \sqrt{3 \pi} \delta v_{b}\right)\right)=\left(\frac{3 M \sigma_{\theta}^{2}}{2 \sqrt{\pi} \sigma_{\theta+u}}\right)\left(1-2 \sqrt{3 \pi} \delta v_{b} \sigma_{\theta+u}\right),
$$

also positive under Standing Assumption 1. These losses are more severe when $M$ is large (because promotion decisions are more important) and when $\delta, v_{b}$, and $\sigma_{u}$ are small (because the distortions are bigger).

\section{Wages and Risk Taking}

In this section, we examine the use of contingent compensation to control managerial behavior. We assume the owner makes a full capital allocation $I=2$ to each division. Under our standing assumption that $\delta v_{b} \sigma_{\theta+u}<1 /(2 \sqrt{3 \pi})$, the tournament characteristics of the internal labor market prompt the managers to inflate risk in a futile effort to increase the chance of promotion. Increasing risk from $\sigma_{\theta+u}$ to $\sigma^{\max } \equiv 1 /\left(2 \sqrt{3 \pi} \delta v_{b}\right)$ reduces the mean outcome for the division and degrades the owner's promotion decisions, costing him money. One possible remedy is for the owner to offer a wage payment when the contracting variable $y$ indicates good performance. Because any misuse of resources reduces $x$, it also reduces the manager's probability of receiving the wage.

Recall that the manager receives wage $w$ when a good signal $y=1$ is observed, and $\alpha$ is the probability that the signal is actually informative rather than random. Manager $i$ chooses $\sigma_{i}$ to maximize his expected payoff:

$$
\Pi_{i}=w \operatorname{Pr}\left[y_{i}=1\right]+Z \operatorname{Pr}\left[i^{*}=i\right]=w E\left[y_{i}\right]+Z W\left(\sigma_{i}\right)
$$

with $E\left[y_{i}\right]$ given by (4) and the promotion probability $W\left(\sigma_{i}\right)$ defined by (7). An increase in risk shifts the distribution of outcomes $x$ to the left at a rate proportional to the extra variance. This reduces the probability that $y=1$, 
thereby reducing the manager's expected wage. Specifically:

$$
\frac{\partial}{\partial \sigma} w E[y]=-\alpha w \delta v_{b}\left(1+\hat{\sigma}^{2} / \sigma^{2}\right) \phi\left(\delta v_{b}\left[\sigma-\hat{\sigma}^{2} / \sigma\right]\right)<0,
$$

proportional to $\alpha$ and $\delta v_{b}$. This shows that incentive wages will be more powerful when $\alpha$ is large (the contracting variable is more informative) and when $\delta v_{b}$ is large (extra risk reduces wages more dramatically by causing a bigger shift in $E[x])$.

Combining (10) with (8), the marginal effect of higher risk on the manager's expected payoff is

$$
\begin{aligned}
\frac{\partial \Pi}{\partial \sigma}= & -\alpha \delta v_{b} w\left(1+\hat{\sigma}^{2} / \sigma^{2}\right) \phi\left(\delta v_{b}\left[\sigma-\hat{\sigma}^{2} / \sigma\right]\right) \\
& +\frac{2 \hat{\sigma}}{\sigma^{2}} Z \int_{-\infty}^{\infty} \gamma \Phi(\gamma) \phi(\gamma) \phi\left(\delta v_{b}\left[\sigma-\hat{\sigma}^{2} / \sigma\right]+\gamma \hat{\sigma} / \sigma\right) \mathrm{d} \gamma \\
& -2 \delta v_{b} Z\left(1+\hat{\sigma}^{2} / \sigma^{2}\right) \int_{-\infty}^{\infty} \Phi(\gamma) \phi(\gamma) \phi\left(\delta v_{b}\left[\sigma-\hat{\sigma}^{2} / \sigma\right]+\gamma \hat{\sigma} / \sigma\right) \mathrm{d} \gamma .
\end{aligned}
$$

Because $\sigma=\hat{\sigma}$ in equilibrium, we can evaluate (11) at $\sigma=\hat{\sigma}$ to get the firstorder condition

$$
\frac{\partial \Pi}{\partial \sigma}=\frac{1}{2 \sqrt{3} \pi}\left(\frac{1}{\sigma}-\frac{1}{\sigma^{\text {max }}}\right) Z-\frac{\sqrt{2} \alpha \delta v_{b}}{\sqrt{\pi}} w=0 .
$$

Absent an incentive wage, the managers will choose $\sigma=\sigma^{\max }$, but a positive $w$ will induce them to add less risk, $\sigma<\sigma^{\max }$. By offering a large-enough wage, the owner can induce any desired risk level between $\sigma_{\theta+u}$ and $\sigma^{\max }$. To induce risk-level $\sigma$, (12) implies that the owner must offer the wage

$$
w=\left(\frac{1}{2 \sqrt{3} \pi \sigma}-\frac{\delta v_{b}}{\sqrt{\pi}}\right) \frac{\sqrt{2 \pi} Z}{2 \delta v_{b} \alpha}=\frac{Z}{\sqrt{2} \alpha}\left(\frac{\sigma^{\max }}{\sigma}-1\right) .
$$

It is immediately clear from (13) that if $\alpha$ is small or $Z$ is large, providing compensation incentives will be too expensive: the wage cost is proportional to $Z / \alpha$.

In equilibrium, each manager receives the wage payment half the time, yielding an average compensation cost of $3 w / 2$ to the owner. The owner's expected payoff is

$$
\begin{aligned}
V_{0}+V_{1}= & 3 E[x]-3 w / 2+M E\left[\theta_{i^{*}}\right]-Z \\
= & 3\left[v_{a}+v_{b}\left(1-\delta\left(\sigma^{2}-\sigma_{\theta+u}^{2}\right)\right)-2\right]-\frac{3 Z}{2 \sqrt{2} \alpha}\left(\frac{\sigma^{\max }}{\sigma}-1\right) \\
& +\frac{3 M \sigma_{\theta}^{2}}{2 \sqrt{\pi} \sigma}-Z,
\end{aligned}
$$


and he chooses the wage $w$ to maximize $V_{0}+V_{1}$. The $\sigma$ that the owner chooses to induce may be interior or may be at either extreme, $\sigma_{\theta+u}$ or $\sigma^{\max }$.

Proposition 4. If either $\alpha$ is sufficiently small or $Z$ is sufficiently large, the owner optimally sets $w=0$; providing wage incentives is too expensive. On the other hand, if $\alpha$ is sufficiently large and $Z$ is sufficiently small, an owner who provides full capital allocations to all managers will offer wage incentives, setting $w>0$.

Proof. See the Appendix.

When the promotion prize $Z$ is large, the tournament-induced incentives to add risk are very strong, making it too costly to provide countervailing wage incentives. When $\alpha$ is close to zero, providing wage incentives is very inefficient because the link between performance and wages ( $x$ and $y$ ) is weak. But if the tournament-induced incentives are not too strong and wage contracts have a tight-enough link to performance, the owner will offer some incentive payments.

\section{Capital Allocation}

We now consider capital budgeting policy when the owner cannot achieve first best, to see whether in equilibrium capital is rationed. As we saw earlier, the first best is not achieved under our standing assumption that $\delta v_{b} \sigma_{\theta+u}<1 /(2 \sqrt{3 \pi})$. We assume, henceforth, that $\alpha=0$; since wages provide no incentives when $\alpha=0$, the owner will set $w=0 .{ }^{15}$ This simplifies matters by allowing us to focus solely on capital allocation without adding qualifications about optimal wages.

If the owner restricts division $i$ 's capital to $I=1$, and the manager adds noise $s_{i}$, the division's outcome is

$$
x_{i}=\theta_{i}+v_{a}\left(1-\delta s_{i}^{2}\right)+u_{i}+s_{i} \epsilon_{i}-1 .
$$

There are two differences compared to the case of full capital allocations. The first is that the value $v_{b}-1$ from project $b$ is forfeited. The second is that each unit of variance added by the manager destroys value $\delta v_{a}$ rather than $\delta v_{b}$; the misallocation of resources for a more profitable project destroys more value.

However, since it is more costly to divert resources from a superior project, the manager would add less noise when capital is rationed-perhaps no noise at all. ${ }^{16}$ A lesser degree of risk-altering distortions under capital rationing has

\footnotetext{
15 Assuming $\alpha=0$ is stronger than necessary. So long as $Z / \alpha$ is large, the owner will forgo wage incentives, because the wage cost is proportional to $Z / \alpha$.

16 The manager's concern is not the foregone profits, per se, but that the lower mean outcome leads the owner to less favorable inferences about his ability.
} 
two positive effects on the owner's expected payoff. First, the manager utilizes corporate resources more efficiently, which enhances first-period value. Second, the division's performance becomes more informative about the manager's talent. This improves the owner's promotion decisions, thereby creating additional second-period value. We show that these two effects combined can more than offset the sacrificed profits associated with project $b$. Thus, rationing is sometimes beneficial.

Recall that the new CEO creates additional value after promotion, $V_{1}=$ $M E\left[\theta_{i^{*}}\right]-Z$, where the multiplier $M>1$ reflects the greater effect of managerial talent when the manager's span of control increases. Larger $M$ implies that efficient promotion decisions increase in importance relative to date-0 production efficiency. The next proposition states the intuitive result that if $M$ is large enough, equilibrium involves some rationing of capital.

Proposition 5. When the span-of-control parameter $M$ is sufficiently large, the optimal capital allocation has rationing $\left(I_{i}=1\right)$ for at least one division. If all divisions are rationed, the managers add strictly less variance than under full capital allocations.

Proof. To see that rationing is efficient for large $M$, consider the policy of rationing capital to all three divisions. This sacrifices all the potential firstperiod profits from project $b$. However, the analysis of Section 2 implies that managers will add less variance under such an allocation, so fewer promotion mistakes will be made. If $v_{a}$ is large enough that $\delta v_{a} \sigma_{\theta+u} \geq 1 /(2 \sqrt{3 \pi})$, then the managers will add no excess variance when they are all rationed: $\sigma$ is simply $\sigma_{\theta+u}$. If $v_{a}$ is smaller, the rationed managers will add some variance, but less than they would add with full capital allocations: $\sigma$ will be $1 /\left(2 \sqrt{3 \pi} \delta v_{a}\right)$, which is smaller than $\sigma^{\max }=1 /\left(2 \sqrt{3 \pi} \delta v_{b}\right)$. When $M$ is sufficiently large, the increase in $V_{1}$ swamps the decrease in $V_{0}$. Full capital allocations to all divisions is therefore a suboptimal scheme when $M$ is large.

\subsection{Rationing all divisions}

We see from Proposition 5 that rationing capital is sometimes an efficient solution when managers can alter risk in unobservable ways. The optimal arrangement may even ration capital to all divisions in order to generate the most precise information possible about the ability of divisional managers; when $M$ is large, this is definitely better than providing full allocations of capital to all the managers. The next proposition compares these two extremes in more detail: full allocations to all divisions versus rationing all divisions.

Proposition 6. When $M$ is sufficiently large, rationing capital to each division is better for the owner than providing full capital allocations. For a fixed value of $M$, rationing all divisions is better if $\delta$ or $v_{b}$ is small enough. 
Proof. It is straightforward to verify that the change in total value $V_{0}+V_{1}$ from restricting each division to one unit of capital instead of two is

$$
-3\left(v_{b}-1\right)+\left(\frac{1}{4 \pi \delta v_{b}}-3 \delta v_{b} \sigma_{\theta+u}^{2}\right)+\left(\frac{3 M \sigma_{\theta}^{2}}{2 \sqrt{\pi} \sigma_{\theta+u}}\right)\left(1-2 \sqrt{3 \pi} \delta v_{b} \sigma_{\theta+u}\right)
$$

if $v_{a}>1 /\left(2 \sqrt{3 \pi} \delta \sigma_{\theta+u}\right)$, and is

$$
-3\left(v_{b}-1\right)+\left(\frac{1}{4 \pi \delta v_{a} v_{b}}+3 \delta \sigma_{\theta+u}^{2}\right)\left(v_{a}-v_{b}\right)+3 \sqrt{3} \delta \sigma_{\theta}^{2} M\left(v_{a}-v_{b}\right)
$$

if $v_{a}<1 /\left(2 \sqrt{3 \pi} \delta \sigma_{\theta+u}\right)$. In either case, only the first of the three terms is negative; the second and third are positive. Since the third term grows with $M$, the entire expression is clearly positive when $M$ is large. As $\delta \downarrow 0$, the second term explodes, also making the expression positive. Finally, the expression is positive as $v_{b} \downarrow 1$ because the negative term vanishes.

As explained above, large $M$ favors rationing because more precise signals of $\theta$ add a lot of value by improving promotion decisions. Small $v_{b}$ favors rationing because it means that the project being sacrificed did not add much value anyway. Small $\delta$ induces managers to add more variance when capital is not rationed (Proposition 3), and this favors rationing for two reasons. First, the added variance reduces the value of project $b$, so rationing does not forfeit as much date- 0 value. ${ }^{17}$ Second, the extra variance reduces the quality of promotion decisions, so the gain from eliminating the noise is greater. The parameter $\sigma_{u}$ has the same comparative statistics as $\delta$ because small $\sigma_{u}$ has these same two effects plus a third: it increases the wealth achievable under first-best promotion decisions because there is less noise in the owner's observations, and this makes rationing more attractive. However, unlike $\delta$ and $v_{b}$, small $\sigma_{u}$ alone is not enough to guarantee that rationing is better than full investment. ${ }^{18}$ The comparative statistics for $\sigma_{\theta}$ are ambiguous. Like $\delta, v_{b}$, and $\sigma_{u}$, small $\sigma_{\theta}$ makes rationing less costly because it forfeits less $V_{0}$ wealth due to severe managerial distortions. However, small $\sigma_{\theta}$ also means that the benefits of rationing (improved promotion decisions) are smaller because the managers are likely to be very close in talent.

Risk distortions become more costly when the managers are rationed, as each unit of excess variance destroys value $\delta v_{a}$ instead of $\delta v_{b}$. But rationing reduces the distortion $s$, and the risk reductions are large enough that less value gets destroyed in equilibrium: $\delta v_{a} s^{2}$ with rationed capital is smaller than $\delta v_{b} s^{2}$ with

17 Differentiate (9) to see that smaller $\delta$ implies greater destruction of date-0 value through variance manipulation. Smaller $v_{b}$ has the same effect on risk distortions.

18 To see why small $\sigma_{u}$ alone is not enough to make rationing attractive, recall that Standing Assumption 1, $\delta v_{b} \sigma_{\theta+u}<1 /(2 \sqrt{3 \pi})$, means that managers add some excess variance. If $\delta v_{b} \sigma_{\theta}$ is close to $1 /(2 \sqrt{3 \pi})$, these risk distortions will destroy only a small amount of value, so rationing may not be worthwhile even if $\sigma_{u}$ is tiny. 
full capital allocations. (This positive effect on $V_{0}$ is captured by the second term in the proof of Proposition 6.) The improved production efficiency comes at the cost of forfeiting the NPV of project $b$, which directly reduces $V_{0}$. (This direct effect is captured by the first term in that proof.)

\subsection{Partial Rationing}

Thus far, we have examined managerial behavior when the owner makes identical capital allocations to all divisions, but it might be in the owner's interest to ration only some of the divisions. This subsection considers the case where one of the managers (manager 1) is rationed and the other two get full allocations; similar logic applies to the case where two of the three divisions are rationed. We continue to focus on equilibria that are symmetric in the sense that the managers who receive identical capital allocations choose identical strategies.

For this subsection only, we impose a tighter bound on $\delta v_{b} \sigma_{\theta+u}$ than the bound in our standing assumption. We now assume that

$$
\delta v_{b} \sigma_{\theta+u}<\frac{1}{2(1+\sqrt{2}) \sqrt{\pi}} .
$$

This tighter bound guarantees that the two types of equilibria in Proposition 7 are the only possible equilibria.

Proposition 7. Assume that (15) holds and suppose the owner rations capital to division 1 only: $I_{1}=1, I_{2}=I_{3}=2$. Let $\sigma_{1 x}=\sigma\left(x_{1}\right)$ denote the risk of the rationed division, and let $\sigma_{2 x}=\sigma\left(x_{2}\right)=\sigma\left(x_{3}\right)$ denote the risk of the nonrationed divisions. Depending on the parameters, the subgame equilibrium may have $\sigma_{1 x}=\sigma_{\theta+u}$ or $\sigma_{1 x}>\sigma_{\theta+u} ; \sigma_{2 x}$ is always greater than $\sigma_{\theta+u}$. The owner (correctly) anticipates that managers will add risk as follows.

1. If manager 1 adds no variance, $\sigma_{1 x}=\sigma_{\theta+u}$, the nonrationed managers add variance such that $\sigma_{2 x}=\sigma_{\theta+u} / \sqrt{K}$, where $K$ is the unique real solution to

$$
K(3+K)-2 \delta v_{b} \sigma_{\theta+u} \sqrt{\pi(1+K)(2+K)}(\sqrt{1+K}+\sqrt{2 K})=0 .
$$

2. If manager 1 adds variance, then $\sigma_{1 x}=\sqrt{K} /$ $\left(\delta v_{a} \sqrt{2 \pi(1+K)(2+K)}\right)$, and the nonrationed managers add variance such that $\sigma_{2 x}=\sigma_{1 x} / \sqrt{K}$, where $K$ is the unique real solution to

$$
\sqrt{K}(3+K)-(2 \sqrt{K}+\sqrt{2(1+K)}) \frac{v_{b}}{v_{a}}=0
$$

Proof. See the Appendix. 
When project $a$ is good enough, the rationed manager adds no risk, but the nonrationed managers do. In the case where all managers add risk, the nonrationed managers add more risk, although this is far from obvious by a cursory inspection of the equations in Proposition 7. We state this as the next result.

Proposition 8. Assume that (15) holds. When one division is rationed and the others receive full capital allocations, the nonrationed managers add strictly more risk than the rationed manager.

Proof. See the Appendix.

The intuition for Proposition 8 is straightforward. Managers with full capital allocations can add noise by distorting project $b$, with expected loss of profits $\delta v_{b} s^{2}$. Managers who are rationed must distort project $a$ when adding noise, reducing profits at a faster rate- $-\delta v_{a}$ per unit of variance. This makes it natural to expect managers with full allocations to add at least as much noise as rationed managers. One might imagine that if for some reason the owner expected the nonrationed managers to add less risk, the managers would, in fact, behave that way. Our proposition shows that this does not happen.

We saw in Section 4.1 that the value destroyed through variance manipulation is reduced when all divisions are rationed, even though each unit of excess variance is more onerous $\left(\delta v_{a}>\delta v_{b}\right)$. When only division 1 is rationed, each unit of excess variance in that division is especially costly. However, manager 1 distorts less aggressively, and the improved behavior is significant enough that less value is wasted in that division than in the other divisions: $\delta v_{a} s_{1 x}^{2}<\delta v_{b} s_{2 x}^{2}$. This is obviously true when manager 1 adds no noise, but it is also true when $s_{1 x}$ is positive. ${ }^{19}$

Differential capital allocations affect the promotion tournament in a surprising way, as our next result shows.

Proposition 9. Assume that (15) holds and suppose the owner rations capital to division 1 only. The probability that manager 1 is promoted is greater than $1 / 3$, and the probability that each of the other managers is promoted is less than $1 / 3$.

Proof. See the Appendix.

19 Using Part 2 of Proposition 7, the difference in value destroyed through risk distortions is

$$
\delta v_{b} s_{2}^{2}-\delta v_{a} s_{1}^{2}=\delta \sigma_{\theta+u}^{2}\left(v_{a}-v_{b}\right)+\delta v_{a} \sigma_{1}^{2}\left(\frac{3-K-\sqrt{2 K(1+K)}}{2 K+\sqrt{2 K(1+K)}}\right),
$$

where $0<K<1$ by Proposition 8. Over this interval, $3-K-\sqrt{2 K(1+K)}>0$, which implies $\delta v_{a} s_{1}^{2}<\delta v_{b} s_{2}^{2}$. 
The manager who is rationed is more likely to be promoted even though all managers are identical ex ante and each is maximizing his probability of promotion. Because rationing induces manager 1 to add less noise to divisional performance, the owner's ex post estimate of his talent is more variable, so it is more likely that he is evaluated to be the best (or worst) of the three. In contrast to models of empire-building managers, the manager here would volunteer to be the one who is rationed. ${ }^{20}$

It is also interesting that typical accounting measures of performance are likely to indicate that division 1 has the best performance. For example, suppose project $a$ is better than project $b$ because the project investment $I=1$ generates more revenue and a higher profit margin. Then, the expected asset turnover, profit margin, return on assets, and ratio of market value to book value would all be higher for division 1 than for the other divisions. Even though the three managers have identical talent (and even though the divisions have identical investment opportunities), the most likely outcome is that the rationed manager is promoted and that accounting measures of performance make this division appear the most successful.

Things would be more complicated if the divisions were not identical, but it is still plausible that one would see the manager of the best division promoted more frequently even if the managers have identical talent. For motivation, consider the setting of Harris and Raviv (1996), where the efficient way of coping with information asymmetries is to give the worst division excess capital and ration the best division. Our logic suggests that managers of poorer divisions would then (rationally) add more noise, and managers of better divisions would add less noise. The result is that, even when the true talent levels are identical, better divisions are more likely to produce the new CEO.

\subsection{Rationing versus wages}

Throughout this section, we have assumed that wages are impotent for controlling risk distortions $(\alpha=0)$. In general, the cost to the owner of providing wage incentives depends on $Z / \alpha$, as was shown in Section 3. The cost to the owner of controlling risk distortions by rationing capital is independent of both $Z$ and $\alpha$; the cost he bears is the foregone profits from project $b$. For this reason, rationing is particularly important when tournament considerations loom large ( $Z$ is big), which motivates us to focus primarily on the capital allocation mechanism rather than the wage mechanism.

In general, rationing will be more attractive to the owner if $Z$ is large, $\alpha$ is small, or $v_{b}$ is fairly close to 1 . Wage incentives will be more attractive if

20 We have assumed that the physical use of capital is contractible. (See Section 1.1.) If this were not the case, then a manager might seek a way to "self-ration" by investing in project $a$ only. For such a scheme to work, the self-rationing would have to be observable to the owner and the manager would have to find a way to guarantee that the second unit of capital would not be subject to variance manipulation, perhaps by posting it in some sort of collateral account. Self-rationing is not an issue when the owner can specify which projects are to be taken, as we have assumed. 
$Z / \alpha$ is small or $v_{b}$ is large. ${ }^{21}$ If $Z / \alpha$ is large (obviating wages) and $v_{b}$ is large (obviating rationing), the owner will choose to live with the extra risk, allowing the managers to set $\sigma=\sigma^{\max }$.

\section{Extensions}

In this section, we discuss some possible extensions of our basic model. We consider the effects of risk-altering investment distortions on optimal organizational scope, the effects of possible cross-firm promotions of managers, and the potential advantages to a firm of committing to narrow the set of contenders for the CEO position.

\subsection{Organizational scope}

In this article, we have taken the structure of the firm as given and have shown how competition among divisional managers for the CEO slot produces inefficiencies when the candidates can unobservably alter risks. For modeling simplicity, we considered only three divisions, but even greater distortions would result from a larger pool of contenders. Figure 2 illustrates how risk taking changes as the number of divisions increases, using the example parameters from Figure 1.22

Our analysis suggests some implications about whether divisions should be combined within a firm (and how many) or should stand apart. There are other factors that may make the conglomerate form desirable or undesirable, but our model points out an interesting trade-off that arises from learning about the talent of the divisional managers. Consider the situation where the only advantage of a conglomerate over a group of stand-alone firms is that it allows an especially talented CEO to take value-creating actions in a broader domainone can have Jack Welch manage the entire enterprise rather than having Jack Welch manage one division and several lesser lights manage the others. This suggests that conglomerates should have many divisions.

However, having more divisions in the firm induces greater strategic distortions by the managers who hope to be the next CEO. This is costly due to lost value from suboptimal operating decisions by the divisions (and perhaps due to capital rationing to reduce such distortions), and also because the additional noise makes promotion decisions less efficient. In the simple setting of our model, these distortions can be avoided completely by limiting the firm

21 Although it is true that large $v_{b}$ makes wages more attractive than rationing, wage incentives will not be used if $v_{b}$ is very large. In that case, there is no problem to begin with-the owner can achieve first best without any control mechanism when $\delta v_{b} \sigma_{\theta+u}>1 /(2 \sqrt{3 \pi})$ (Proposition 2).

22 With full capital allocations, managerial choices in the symmetric equilibrium when there are $n$ divisions satisfy

$$
\left.\frac{\partial W}{\partial \sigma}\right|_{\sigma=\hat{\sigma}}=-(n-1) \int_{-\infty}^{\infty} \Phi(\gamma)^{n-2} \phi(\gamma)^{2}\left(2 \delta v_{b}-\frac{\gamma}{\sigma}\right) \mathrm{d} \gamma=0
$$




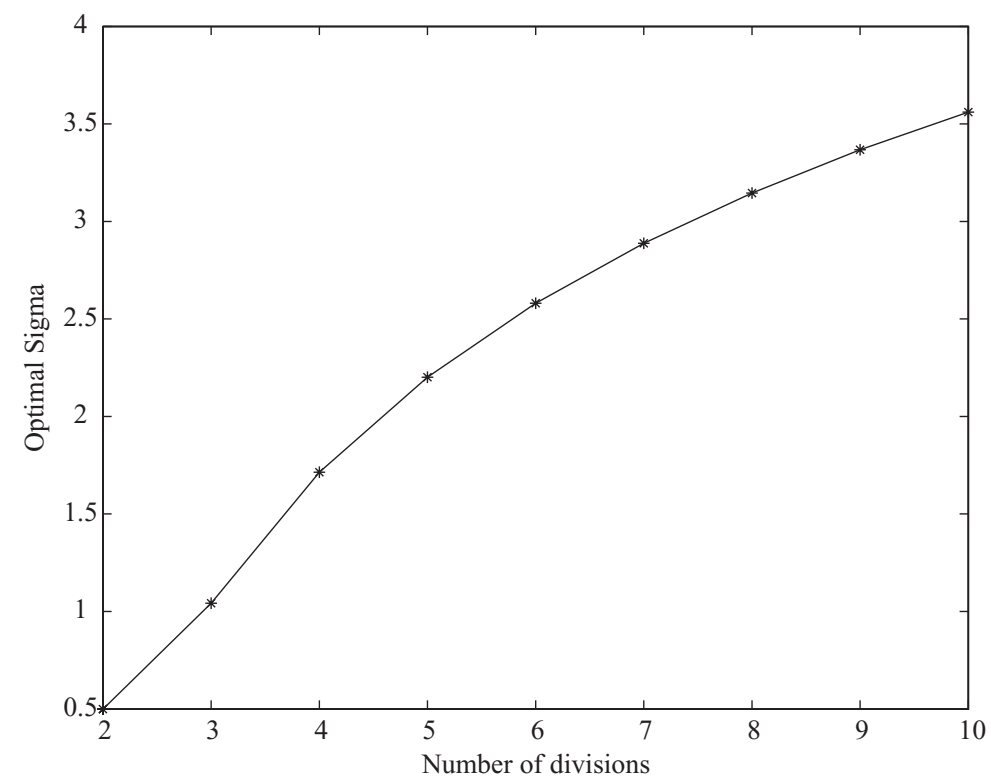

Figure 2

Risk taking as a function of the number of divisions

The figure plots the equilibrium value of $\sigma$ as a function of the number of managers in the promotion tournament, assuming all divisions receive full capital allocations. The figure is based on the parameters given in Figure 1. The model considered in the article has $n=3$, with the resulting $\sigma=1.0424$. When there are more divisions, risk taking is more extreme.

to one or two divisions (Proposition 1). This generates the best possible operating decisions without rationing capital and without distorting promotion decisions.

For instance, in our setting with three divisions, one could organize operations as the three-division conglomerate of the model or as three separate "focused" firms. ${ }^{23}$ Assume that the $M$ and $Z$ of the model are now $M / 3$ and $Z / 3$ for each of the focused firms. ${ }^{24}$ When all managers have full capital allocations, date- 0 production is efficient for the focused organization, avoiding the loss of $V_{0}$ value calculated in (9), $1 /\left(4 \pi \delta v_{b}\right)-3 \sigma_{\theta+u}^{2} \delta v_{b}$. The drawback of focus is that the average talent of the three new CEOs is just the average talent of the pool of divisional managers, namely zero. With the conglomerate structure, the average talent is $E\left[\theta_{i^{*}}\right]=3 \sqrt{3} \sigma_{\theta}^{2} \delta v_{b}$, increasing the $V_{1}$ value by $3 \sqrt{3} M \sigma_{\theta}^{2} \delta v_{b}$.

23 In fact, under our assumptions, organizing operations as three separate firms is dominated by a structure with one single-division firm and one two-division firm. Combining two divisions dominates separating them because it eliminates the incentives to add variance (Proposition 1) and it generates higher average CEO talent because the better performing of the two managers can be promoted. Analyzing this structure generates the same comparative statistics as three stand-alone firms, so we focus on the simpler structure.

24 That is, we are holding aggregate CEO compensation fixed at $Z$ for our thought experiment. Depending on the structure of the labor market, the choice of organization structure might also affect this aggregate CEO compensation. 
Combining these pieces, the value difference between the conglomerate and the focused organization works out to

$$
3 \sqrt{3} M \sigma_{\theta}^{2} \delta v_{b}-\left(\frac{1}{4 \pi \delta v_{b}}-3 \sigma_{\theta+u}^{2} \delta v_{b}\right) .
$$

This implies that large values of $M, \sigma_{\theta}, \sigma_{u}, \delta$, and $v_{b}$ favor conglomeration, and small values of these parameters favor focus. The finding is summarized in Proposition 10.

Proposition 10. The net benefit to conglomeration is increasing in the span of control $M$, the uncertainty about managerial ability $\sigma_{\theta}$, the fundamental noise $\sigma_{u}$, the value loss from distortion $\delta$, and the payoff on the inferior project $v_{b}$.

Large values of the first two parameters favor conglomeration for fundamental reasons. Large $M$ implies that there is a lot to be gained by giving the best manager a greater span of control. Similarly, large $\sigma_{\theta}$ means there are probably large talent differences among managers; conglomeration (usually) allows the best manager to control the entire organization rather than leaving most of it to be run by significantly inferior managers.

Large values of the last three parameters favor conglomeration because of their effects on managerial risk taking. Large $\delta$ and $v_{b}$ make it costlier for managers to add variance, so promotion decisions in a conglomerate are not distorted so severely. Large $\sigma_{u}$ has the same effect, but indirectly. When the fundamental shock $u$ has high variance, the owner's rule for revising estimated managerial talent is less sensitive to performance, making it less tempting for managers to unobservably add variance. As a result, promotion mistakes in conglomerates are not so much worse than in focused organizations.

Familiar measures would provide plausible empirical proxies for some of the parameters. For instance, one could use the variance of earnings or of return on assets as a proxy for $\sigma_{u}^{2}$. Higher variance then suggests more benefits from conglomeration, quite apart from any desire for diversification. The parameter $v_{b}$ captures the profitability of the marginal project that is a candidate for rationing. Recalling that the required investment in the model has been standardized to 1 , and that $v_{b}$ is the value of the project, Tobin's $q$ is the obvious empirical proxy. Ceteris paribus, higher- $q$ firms would have less managerial distortion and would therefore gain more from conglomeration.

Certainly, one factor producing variation in firm performance within an industry is the ability of managers. So measures of cross-firm performance variability for an industry are possible proxies for the industry's $\sigma_{\theta}^{2}$, the variance of managerial talent. The model then predicts that industries where performance is more homogeneous will tend to have more focused firms, and industries with more variation will tend to have more conglomerates. 
Our approach suggests that conglomerates will form when the benefits of learning about managerial ability are greatest, and when the costs of rationing current capital are lowest. It is plausible that managerial ability is most valuable for growth projects in which the strategies needed to maximize profitability have not yet been reduced to routines. ${ }^{25}$ Our model suggests that when the gains that accrue to learning about managerial ability decline, firms will increase their focus by selling divisions and by engaging in spin-offs or equity carve-outs. This implies that a firm that has relatively few growth opportunities will tend to engage in refocusing activity (e.g., by executing a leveraged buyout and selling off noncore assets; see Jensen 1986).

The span-of-control parameter $M$ measures the importance of CEO talent for firm performance. In a competitive labor market, one would expect this to be reflected in executive compensation. Controlling for other factors known to influence $\mathrm{CEO}$ compensation, high residual compensation in an industry is a possible proxy for high $M$. The implication of our model is then that conglomeration is more attractive in industries with positive residual compensation and focus is more attractive in industries with negative residual compensation.

\subsection{Internal and external labor markets}

Our model focuses on competition for promotion within the firm. Of course, in addition to this internal labor market, there is an external market for CEOs. One can imagine that the owner compares the estimated talent (and cost) of the best internal candidate with the estimated talent (and cost) of external candidates when choosing the new CEO. Limited ability to observe performance across firms will limit learning about managers' abilities, so that the managerial labor market cannot re-assort managers to firms perfectly in the next period. But as long as there is some observability, managers will be in a spontaneous crossfirm tournament in which better managers will be hired next period for more important projects. Our approach suggests that this open-market tournament will sometimes be associated with inefficient choice of project variance and capital rationing as managers try to reach the upper tail of the performance distribution. Although in our model, distortions are absent from a firm with one or two divisions, an external labor market would upset this happy outcome.

So, both limits on cross-firm observability and project choice distortions make it costly to organize stand-alone divisions as firms. Greater within-firm observability provides a simple reason to form conglomerates, in addition to the span-of-control reason in Section 5.1.

\subsection{Narrowing the field of contenders}

When there is interest in CEO succession, the board of directors sometimes makes it clear that a few internal candidates are on the "inside track" for the

25 Formally, this greater uncertainty about the value that a manager can create would be captured in the model by a higher variance of manager talent, $\sigma_{\theta}^{2}$. 
top job. It may seem peculiar to eliminate potential CEO candidates who could turn out to be great CEOs. Our model suggests that such an announcement can maximize shareholder wealth even when the firm is satisfied with the performance of the eliminated candidates. For example, in our setting with only three divisions, an announcement that narrows the field of CEO contenders from three to two eliminates the incentives of all managers to distort production in order to add variance (Proposition 1). Thus, narrowing the field avoids the losses due to inefficient production quantified in (9) and also provides the owner with the most precise possible signals of the talent of managers 1 and 2 , making it more likely that the new CEO will be the more talented of the two. The benefits of eliminating one contender will be large when $\delta, v_{b}$, and $\sigma_{u}$ are small, because that is when managers distort very aggressively.

The drawback of eliminating a manager from consideration is that one-third of the time, that manager is the one who would have been the best CEO. This drawback looms large when $\sigma_{\theta}$ is big (i.e., when there are likely to be substantial talent differences among the managers). Thus, a decision to narrow the field of contenders will hurt the owner when $\sigma_{\theta}$ is large (eliminating a manager forfeits a lot of potential CEO value) and also when $\delta, v_{b}$, and $\sigma_{u}$ are large (managers are not distorting very much, so little value is added by eliminating the excess risk). Narrowing the field may help the owner in the opposite circumstances. ${ }^{26}$

Of course, maintaining a narrowed-field policy raises the issue of time consistency. Suppose the field has been narrowed to managers 1 and 2, but then division 3 turns in outstanding performance, leading the owner to conclude that manager 3 would be the best CEO. The owner then wishes to renege on the previous announcement and promote manager 3 . But if the owner will, in fact, renege when it is convenient, and the managers understand this, then the initial announcement will not have its desired effect. When the horse race is narrowed to two, everyone will behave as if there are still three horses in the race because, in fact, there are three horses in the race.

One effective method of committing to a narrow field of candidates is to write in their compensation contracts a guarantee that one of the two will succeed the current CEO. This tactic was recently employed at Viacom, where Tom Freston and Leslie Moonves had clauses in their contracts ensuring that one of them would succeed Sumner Redstone (Flint 2004).

\section{Conclusion}

We have presented a model in which three divisional managers with unknown ability compete for promotion to CEO. The owner uses divisional performance

26 Suppose we compare a policy of narrowing the field from three managers to two against a "default" policy of full capital allocations, no wage incentives, and a full field of contenders. One can show that narrowing the field is better than the default policy when $\delta v_{b} \sigma_{\theta+u}$ is less than $1 /(3 \sqrt{3 \pi})$. 
to assess management talent, and managers can unobservably add variance to the division's operations by diverting resources from their best use. Increasing the variance of the distribution is an attempt to improve the chance of being the top-ranked manager. The distortions are very pronounced if there is likely to be a tight race for succession (i.e., if the variance of management talent is small). The excess variance creates inefficiencies in production and inefficiencies in promotion, since the additional noise makes it more difficult for the owner to determine which manager is most talented.

When the payoff for winning the promotion tournament is not too large and there is a contractible variable sufficiently correlated with divisional performance, incentive wages can be used to reduce these inefficiencies. But, when tournament incentives are pronounced or the contracting variable is noisy, using capital allocation is a better avenue.

Rationing capital to one or more divisions can be an efficient way to alleviate these distortions. When capital is rationed, the manager invests in only the best projects, making it more costly to divert resources. Managers who are rationed therefore add less variance, so production is more efficient and also more informative about manager talent, leading to better promotion decisions. Rationing is more likely to be optimal when the CEO position is relatively more crucial (compared to divisional management), because that is when the superior information is most valuable. If there is uncertainty about when succession will occur - this is outside our model-rationing will be more useful when there is a high probability that the CEO will be replaced in the near future, because that is when division managers have the strongest incentive to inflate risk. The problem is less severe if the current CEO is relatively young and is performing well, making it likely that he will be in office for a long time to come. ${ }^{27}$

Our analysis offers several empirical implications and implications for managerial policy. Although the managers are identical ex ante, and the divisions have identical investment opportunities, we find that the managers of divisions that are rationed are more likely to be promoted to CEO than the managers of fully funded divisions.

Two benefits of conglomeration are that a highly talented CEO can create value in a broader domain, and that there is likely to be greater within-firm observability of managerial performance. A cost is that a promotion tournament in a conglomerate with many contending divisional managers creates a strong incentive for managers to distort risk. This, in turn, increases the need for capital rationing to control this distortion. We derive several comparative statistic predictions about the kinds of firms that will diversify or engage in focusing transactions, such as spin-offs or equity carve-outs.

27 However, the "success factor" might not be monotone, except for firms at the very pinnacle of the business world. A very successful incumbent CEO is unlikely to be fired, but he or she is more likely to be lured away to greener pastures. 
Owners can sometimes benefit by following the common practice of narrowing the field for possible promotion to CEO. The obvious drawback is that such a policy rules out potentially desirable candidates, but this is sometimes outweighed by the benefit of weakening the incentives to distort risk. This, in turn, reduces the need for owners to ration capital.

Our analysis has focused on a firm with a single stage of promotion, from division manager to CEO. Large organizations have many layers of bureaucracy, and promotion to one level gives the manager entry to a contest for promotion to the next. ${ }^{28}$ Our approach suggests that capital rationing is likely to be compounded at different levels of the hierarchy; a divisional manager may ration his subordinates' capital not only because the capital available to the division is rationed, but to control the behavior of managers within the division. This further rationing may serve to limit risk distortion within the division and generate better information about the quality of competing intradivisional managers.

Mandatory rotation schemes in which managers regularly are shifted between divisions have the effect of widening the tournament in the sense that a manager may have the opportunity to participate in tournaments to head more than one division. Previous authors have suggested that such schemes can be beneficial for controlling agency problems on the part of divisional managers. ${ }^{29}$ Our approach suggests an offsetting cost to mandatory rotation schemes. Widening the scope of promotion tournaments intensifies incentives for risk manipulation by managers. To some extent, the firm can control this problem by rationing capital more severely, but this is also costly. Thus, our approach helps explain why some large firms lack mandatory rotation policies. It further suggests that those firms utilizing mandatory rotation will have greater capital rationing; and that such firms are likely to have poorer growth opportunities, since rationing of capital is less costly if good uses for capital are limited. More broadly, extensions of our approach are likely to have a rich set of implications for the relation between the structure of promotion opportunities within organizations, growth opportunities, and capital rationing.

28 Using data on four organizational levels (from the level of plant manager up to CEO) for 303 publicly traded U.S. firms, Lambert, Larcker, and Weigelt (1993) find that, consistent with tournament theory, compensation is convex in the manager's rank in the hierarchy.

29 In the absence of mandatory rotation, divisional managers may not offer challenging projects to their best employees because visible success in such projects could cause the employee to catch the notice of superiors and earn promotion beyond the domain of the divisional manager. 


\section{Appendix}

\section{A. Properties of Gaussian distributions}

The following properties of the standard normal distribution are used in our results. $\Phi(\cdot)$ represents the standard normal distribution function and $\phi(\cdot)$ represents the standard normal density.

$$
\begin{aligned}
\int_{-\infty}^{\infty} \gamma \Phi(\gamma) \phi(\gamma) \phi(\sqrt{K} \gamma) \mathrm{d} \gamma & =\frac{1}{2 \pi(1+K) \sqrt{2+K}} . \\
\int_{-\infty}^{\infty} \Phi(\gamma) \phi(\gamma) \phi(\sqrt{K} \gamma) \mathrm{d} \gamma & =\frac{1}{2 \sqrt{2 \pi} \sqrt{1+K}} . \\
\int_{-\infty}^{\infty} \gamma \Phi\left(\frac{\gamma}{\sqrt{K}}\right) \phi(\gamma) \phi\left(\frac{\gamma}{\sqrt{K}}\right) \mathrm{d} \gamma & =\frac{K}{2 \pi(1+K) \sqrt{2+K}} . \\
\int_{-\infty}^{\infty} \Phi\left(\frac{\gamma}{\sqrt{K}}\right) \phi(\gamma) \phi\left(\frac{\gamma}{\sqrt{K}}\right) \mathrm{d} \gamma & =\frac{\sqrt{K}}{2 \sqrt{2 \pi} \sqrt{1+K}} . \\
\int_{-\infty}^{\infty} \gamma \Phi(\sqrt{K} \gamma)[\phi(\gamma)]^{2} \mathrm{~d} \gamma & =\frac{\sqrt{K}}{4 \pi \sqrt{2+K}} . \\
\int_{-\infty}^{\infty} \Phi(\sqrt{K} \gamma)[\phi(\gamma)]^{2} \mathrm{~d} \gamma & =1 /(4 \sqrt{\pi}) . \\
\int_{-\infty}^{\infty} \gamma^{2} \Phi(\gamma)[\phi(\gamma)]^{2} \mathrm{~d} \gamma & =1 /(8 \sqrt{\pi}) . \\
\int_{-\infty}^{\infty} \gamma^{3} \Phi(\gamma)[\phi(\gamma)]^{2} \mathrm{~d} \gamma & =1 /(3 \sqrt{3} \pi) . \\
\int_{-\infty}^{\infty} \gamma \Phi(\gamma)^{2} \phi(\gamma) \mathrm{d} \gamma & =1 /(2 \sqrt{\pi}) .
\end{aligned}
$$

\section{B. Proofs of propositions}

Proofs of Proposition 2 and Proposition 3: These propositions make statements about the symmetric equilibrium in the managers' subgame when they receive full capital allocations and no wages. Proposition 2 considers the case $\delta v_{b} \sigma_{\theta+u}>1 /(2 \sqrt{3 \pi})$ and Proposition 3 considers the opposite case. We first show that each manager has a finite optimal response $\sigma^{*}=\sigma^{*}(\hat{\sigma})$ that maximizes his chance of promotion, taking the owner's conjecture $\hat{\sigma}$ and the other managers' behavior $\sigma_{j}=\hat{\sigma}$ as given. We then solve for the symmetric equilibrium and establish the other properties stated in the propositions.

For given owner conjecture $\hat{\sigma}$, a manager chooses his own $\sigma$ to maximize his promotion probability $W(\sigma)$ given by (7). The function $W(\sigma)$ has the following properties that hold for any given $\hat{\sigma}$ :

- It is continuous and differentiable in $\sigma$.

- It is bounded: $0<W(\sigma) \leq 1$.

- $\lim _{\sigma \rightarrow \infty} W(\sigma)=0 .{ }^{30}$

These properties together guarantee the existence of a finite optimal response $\sigma^{*}(\hat{\sigma}) \geq \sigma_{\theta+u}$ that maximizes $W(\sigma)$.

Equilibrium requires that managerial choices confirm the owner's conjectures: the equilibrium $\hat{\sigma}$ satisfies $\sigma^{*}(\hat{\sigma})=\hat{\sigma}$. There are two possibilities for the symmetric equilibrium: either $\sigma=\sigma_{\theta+u}$ or $\sigma$ is an interior solution. An interior solution must satisfy the first-order condition $\partial W /\left.\partial \sigma\right|_{\sigma=\hat{\sigma}}=0$.

30 This limit can be established using the fact that $\Phi(-A)<1 / A$ for all $A>0$. 
The expression for $\partial W / \partial \sigma$ in (8) simplifies greatly when evaluated at $\sigma=\hat{\sigma}$, using properties (A5) and (A6) of the standard normal distribution:

$$
\left.\frac{\partial W}{\partial \sigma}\right|_{\sigma=\hat{\sigma}}=1 /(2 \sqrt{3} \pi \sigma)-\delta v_{b} / \sqrt{\pi} .
$$

If $\delta v_{b} \sigma_{\theta+u} \geq 1 /(2 \sqrt{3 \pi})$, then $\partial W /\left.\partial \sigma\right|_{\sigma=\hat{\sigma}}<0$ for all $\sigma>\sigma_{\theta+u}$. This means that $\sigma=\sigma_{\theta+u}$ is the only possible equilibrium for these parameters. The owner anticipates no excess variance, and it is optimal for each manager to add no variance, as claimed in Proposition 2.

If $\delta v_{b} \sigma_{\theta+u}<1 /(2 \sqrt{3 \pi})$, the first-order condition is

$$
1 /(2 \sqrt{3} \pi \sigma)-\delta v_{b} / \sqrt{\pi}=0
$$

which gives $\sigma=1 /\left(2 \sqrt{3 \pi} \delta v_{b}\right)$. Checking the second derivative shows that this point is a maximum, not a minimum, as follows. Defining $h(\gamma, \sigma)=\delta v_{b}\left[\sigma-\hat{\sigma}^{2} / \sigma\right]+\gamma \hat{\sigma} / \sigma$, the second derivative of $W$ is

$$
\frac{\partial^{2} W}{\partial \sigma^{2}}=-2 \int_{-\infty}^{\infty} \Phi(\gamma) \phi(\gamma) \phi(h(\gamma, \sigma))\left[\frac{\partial^{2} h(\gamma, \sigma)}{\partial \sigma^{2}}-h(\gamma, \sigma)\left(\frac{\partial h(\gamma, \sigma)}{\partial \sigma}\right)\right] \mathrm{d} \gamma .
$$

When evaluated at $\sigma=\hat{\sigma}$, tedious calculations reduce this to $-2\left(\frac{1}{6 \sqrt{3} \pi \sigma^{2}}-\frac{\delta^{2} v_{b}^{2}}{\sqrt{3} \pi}\right)$, which is negative at $\sigma=1 /\left(2 \sqrt{3 \pi} \delta v_{b}\right)$. So, when $\delta v_{b} \sigma_{\theta+u}<1 /(2 \sqrt{3 \pi})$, there is a unique symmetric equilibrium and this equilibrium has $\sigma=1 /\left(2 \sqrt{3 \pi} \delta v_{b}\right)$. The corresponding excess variance is $s^{2}=$ $\left(2 \sqrt{3 \pi} \delta v_{b}\right)^{-2}-\sigma_{\theta+u}^{2}$, which is decreasing in $\delta, v_{b}, \sigma_{\theta}$, and $\sigma_{u}$, as claimed in Proposition 3.

Proof of Proposition 4: We first prove that we have forfeited no generality by assuming that the manager's wage depends only on that division's outcome, rather than the outcomes of all three divisions. Consider a wage contract $w\left(y_{i}, y_{-i}\right)$ that pays manager $i$ based on all the outcomes. Given the owner's expectations $\hat{\sigma}$, the expected payoff for manager $i$ if he chooses $\sigma_{i}$ and the other managers choose $\sigma_{-i}$ is

$$
E\left[w\left(y_{i}, y_{-i}\right) \mid \sigma_{i}, \sigma_{-i}, \hat{\sigma}\right]+Z \cdot W\left(\sigma_{i} \mid \sigma_{-i}, \hat{\sigma}\right) .
$$

In order for the equilibrium strategy to be optimal, choosing $\sigma_{i}=\hat{\sigma}_{i}$ must maximize this payoff, taking as given the choices of the other managers $\sigma_{-i}=\hat{\sigma}_{-i}$ and the owner's conjecture $\hat{\sigma}$. That is, for every possible $\sigma_{i}$, we must have

$$
E\left[w\left(y_{i}, y_{-i}\right) \mid \hat{\sigma}_{i}, \hat{\sigma}_{-i}, \hat{\sigma}\right]+Z \cdot W\left(\hat{\sigma}_{i} \mid \hat{\sigma}_{-i}, \hat{\sigma}\right) \geq E\left[w\left(y_{i}, y_{-i}\right) \mid \sigma_{i}, \hat{\sigma}_{-i}, \hat{\sigma}\right]+Z \cdot W\left(\sigma_{i} \mid \hat{\sigma}_{-i}, \hat{\sigma}\right) .
$$

One can rewrite the manager's expected wage as

$$
\begin{aligned}
E\left[w\left(y_{i}, y_{-i}\right) \mid \sigma_{i}, \sigma_{-i}, \hat{\sigma}\right] & =\int w\left(y_{i}, y_{-i}\right) f\left(y_{i}, y_{-i} \mid \sigma_{i}, \sigma_{-i}, \hat{\sigma}\right) \mathrm{d} y \\
& =\int\left\{\int w\left(y_{i}, y_{-i}\right) f\left(y_{-i} \mid \sigma_{-i}, \hat{\sigma}\right) d y_{-i}\right\} f\left(y_{i} \mid \sigma_{i}, \hat{\sigma}\right) \mathrm{d} y_{i} .
\end{aligned}
$$

Now use the conditional expectation in the braces to define a new contract $\tilde{w}$ that depends on only $y_{i}$, taking as given the equilibrium strategies of the other divisions:

$$
\tilde{w}\left(y_{i}\right)=\int w\left(y_{i}, y_{-i}\right) f\left(y_{-i} \mid \hat{\sigma}_{-i}, \hat{\sigma}\right) d y_{-i} .
$$

Under this simpler contract, the optimality condition for manager $i$ 's equilibrium strategy choice is exactly the same as under the original contract. Namely, for every possible choice $\sigma_{i}$, it must be 
that

$$
\begin{aligned}
& \int\left\{\int w\left(y_{i}, y_{-i}\right) f\left(y_{-i} \mid \hat{\sigma}_{-i}, \hat{\sigma}\right) \mathrm{d} y_{-i}\right\} f\left(y_{i} \mid \hat{\sigma}_{i}, \hat{\sigma}\right) \mathrm{d} y_{i}+Z \cdot W\left(\hat{\sigma}_{i} \mid \hat{\sigma}_{-i}, \hat{\sigma}\right) \\
& \geq \int\left\{\int w\left(y_{i}, y_{-i}\right) f\left(y_{-i} \mid \hat{\sigma}_{-i}, \hat{\sigma}\right) d y_{-i}\right\} f\left(y_{i} \mid \sigma_{i}, \hat{\sigma}\right) \mathrm{d} y_{i}+Z \cdot W\left(\sigma_{i} \mid \hat{\sigma}_{-i}, \hat{\sigma}\right) .
\end{aligned}
$$

This proves that it is valid to restrict attention to wage contracts that depend on the outcome for that manager's division alone.

To prove the conclusions in the proposition, we use the owner's expected payoff $V_{0}+V_{1}$ given in (14). A marginal increase in the wage $w$ will reduce the equilibrium $\sigma$; differentiating (14) gives

$$
-\frac{\partial\left(V_{0}+V_{1}\right)}{\partial \sigma}=\frac{3}{\sigma^{2}}\left(2 \delta v_{b} \sigma^{3}-\frac{Z \sigma^{\max }}{2 \sqrt{2} \alpha}+\frac{M \sigma_{\theta}^{2}}{2 \sqrt{\pi}}\right) .
$$

The first term captures the improved profits from first-period production, the second term captures the additional wage cost, and the third term captures the additional value from better promotion decisions.

The optimal wage depends on the size of $Z$ and $\alpha$. If $Z$ is small enough and $\alpha$ large enough that

$$
\frac{Z}{\alpha} \leq 4 \sqrt{6 \pi} \delta v_{b}\left[2 \delta v_{b}\left(\sigma_{\theta+u}\right)^{3}+\frac{M}{2 \sqrt{\pi}} \sigma_{\theta}^{2}\right],
$$

then we have a corner solution: the owner offers a wage large enough that managers add no risk, i.e., $w=\frac{Z}{\sqrt{2} \alpha}\left(\frac{\sigma^{\max }}{\sigma_{\theta+u}}-1\right)>0$ and $\sigma=\sigma_{\theta+u}$. When $Z / \alpha$ satisfies

$$
4 \sqrt{6 \pi} \delta v_{b}\left[2 \delta v_{b}\left(\sigma_{\theta+u}\right)^{3}+\frac{M}{2 \sqrt{\pi}} \sigma_{\theta}^{2}\right]<\frac{Z}{\alpha}<4 \sqrt{6 \pi} \delta v_{b}\left[2 \delta v_{b}\left(\sigma^{\max }\right)^{3}+\frac{M}{2 \sqrt{\pi}} \sigma_{\theta}^{2}\right],
$$

the owner sets $w=\frac{Z}{\sqrt{2} \alpha}\left(\frac{\sigma^{\max }}{\sigma}-1\right)>0$, where the corresponding equilibrium risk-taking level $\sigma$ solves the first-order condition:

$$
2 \delta v_{b} \sigma^{3}-\frac{Z \sigma^{\max }}{2 \sqrt{2} \alpha}+\frac{M \sigma_{\theta}^{2}}{2 \sqrt{\pi}}=0
$$

Given (B1), the equilibrium $\sigma$ lies between $\sigma_{\theta+u}$ and $\sigma^{\max }$ in this case. Finally, consider the situation when $Z$ is large enough or $\alpha$ is small enough that

$$
\frac{Z}{\alpha} \geq 4 \sqrt{6 \pi} \delta v_{b}\left[2 \delta v_{b}\left(\sigma^{\max }\right)^{3}+\frac{M}{2 \sqrt{\pi}} \sigma_{\theta}^{2}\right] \text {. }
$$

In this case, it is straightforward to verify that the owner's payoff decreases monotonically with the wage, so the owner will optimally set $w=0$ and the managers will choose $\sigma=\sigma^{\max }$.

Proof of Proposition 7: The proposition characterizes equilibrium in the managers' subgame when only division 1 is rationed. The prior means of manager talent are all zero: $\bar{\theta}_{01}=\bar{\theta}_{02}=$ $\bar{\theta}_{03}=0$. The divisional outcomes are

$$
\begin{aligned}
& x_{1}=\theta_{1}+v_{a}\left(1-\delta s_{1}^{2}\right)+u_{1}+s_{1} \epsilon_{1}-1, \\
& x_{2}=\theta_{2}+v_{a}+v_{b}\left(1-\delta s_{2}^{2}\right)+u_{2}+s_{2} \epsilon_{2}-2, \\
& x_{3}=\theta_{3}+v_{a}+v_{b}\left(1-\delta s_{3}^{2}\right)+u_{3}+s_{3} \epsilon_{3}-2 .
\end{aligned}
$$


Upon observing the outcomes $x_{i}$, the owner's posterior mean estimates of manager ability are

$$
\begin{aligned}
& \bar{\theta}_{11}=\frac{\sigma_{\theta}^{2}}{\sigma_{\theta+u}^{2}+\hat{s}_{1}^{2}}\left[x_{1}-v_{a}\left(1-\hat{s}_{1}^{2} \delta\right)+1\right]=\frac{\sigma_{\theta}^{2}}{\sigma_{\theta+u}^{2}+\hat{s}_{1}^{2}}\left[\theta_{1}+u_{1}+s_{1} \epsilon_{1}-\delta v_{a}\left(s_{1}^{2}-\hat{s}_{1}^{2}\right)\right] . \\
& \bar{\theta}_{12}=\frac{\sigma_{\theta}^{2}}{\sigma_{\theta+u}^{2}+\hat{s}_{2}^{2}}\left[x_{2}-v_{a}-v_{b}\left(1-\hat{s}_{2}^{2} \delta\right)+2\right]=\frac{\sigma_{\theta}^{2}}{\sigma_{\theta+u}^{2}+\hat{s}_{2}^{2}}\left[\theta_{2}+u_{2}+s_{2} \epsilon_{2}-\delta v_{b}\left(s_{2}^{2}-\hat{s}_{2}^{2}\right)\right] . \\
& \bar{\theta}_{13}=\frac{\sigma_{\theta}^{2}}{\sigma_{\theta+u}^{2}+\hat{s}_{3}^{2}}\left[x_{3}-v_{a}-v_{b}\left(1-\hat{s}_{3}^{2} \delta\right)+2\right]=\frac{\sigma_{\theta}^{2}}{\sigma_{\theta+u}^{2}+\hat{s}_{3}^{2}}\left[\theta_{3}+u_{3}+s_{3} \epsilon_{3}-\delta v_{b}\left(s_{3}^{2}-\hat{s}_{3}^{2}\right)\right] .
\end{aligned}
$$

Each manager chooses $s_{i}$ to maximize the probability that $\bar{\theta}_{1 i}=\max _{j}\left\{\bar{\theta}_{1 j}\right\}$. It is more convenient to solve the problem in terms of $\sigma_{i}$ and $\hat{\sigma}_{i}$ rather than $s_{i}$ and $\hat{s}_{i}$, where $\sigma_{i}^{2}=\sigma_{\theta+u}^{2}+s_{i}^{2}$ and $\hat{\sigma}_{i}^{2}=$ $\sigma_{\theta+u}^{2}+\hat{s}_{i}^{2}$. In a symmetric equilibrium, the owner expects identical behavior from the nonrationed managers: $\hat{\sigma}_{2}=\hat{\sigma}_{3}$.

\section{The nonrationed managers}

In a symmetric equilibrium, managers 2 and 3 will make identical choices. We present manager 2's optimization; manager 3's problem is analogous. Manager 2 wins promotion if and only if $\bar{\theta}_{12}$ is bigger than both $\bar{\theta}_{11}$ and $\bar{\theta}_{13}$. Referring to (B2)-(B4), the posterior means have the following distributions, where the $\gamma_{i}$ are independent standard normals:

$$
\begin{aligned}
& \bar{\theta}_{11} \sim\left(\frac{\sigma_{\theta}^{2}}{\hat{\sigma}_{1}^{2}}\right)\left[\sigma_{1} \gamma_{1}-\delta v_{a}\left(\sigma_{1}^{2}-\hat{\sigma}_{1}^{2}\right)\right] . \\
& \bar{\theta}_{12} \sim\left(\frac{\sigma_{\theta}^{2}}{\hat{\sigma}_{2}^{2}}\right)\left[\sigma_{2} \gamma_{2}-\delta v_{b}\left(\sigma_{2}^{2}-\hat{\sigma}_{2}^{2}\right)\right] . \\
& \bar{\theta}_{13} \sim\left(\frac{\sigma_{\theta}^{2}}{\hat{\sigma}_{3}^{2}}\right)\left[\sigma_{3} \gamma_{3}-\delta v_{b}\left(\sigma_{3}^{2}-\hat{\sigma}_{3}^{2}\right)\right] .
\end{aligned}
$$

Since $\hat{\sigma}_{2}=\hat{\sigma}_{3}$ and manager 2 expects the other managers to follow the equilibrium strategies, he anticipates winning promotion if

$$
\left(\frac{\sigma_{\theta}^{2}}{\hat{\sigma}_{2}^{2}}\right) \sigma_{2} \gamma_{2}-\delta v_{b} \sigma_{\theta}^{2}\left(\frac{\sigma_{2}^{2}}{\hat{\sigma}_{2}^{2}}-1\right)>\frac{\sigma_{\theta}^{2}}{\hat{\sigma}_{1}} \gamma_{1} \quad \text { and } \quad\left(\frac{\sigma_{\theta}^{2}}{\hat{\sigma}_{2}^{2}}\right) \sigma_{2} \gamma_{2}-\delta v_{b} \sigma_{\theta}^{2}\left(\frac{\sigma_{2}^{2}}{\hat{\sigma}_{2}^{2}}-1\right)>\frac{\sigma_{\theta}^{2}}{\hat{\sigma}_{2}} \gamma_{3} \text {, }
$$

that is, if

$\gamma_{2}>\max \left\{\frac{\hat{\sigma}_{2}^{2}}{\hat{\sigma}_{1}^{2}} \frac{\hat{\sigma}_{1}}{\sigma_{2}} \gamma_{1}, \frac{\hat{\sigma}_{2}}{\sigma_{2}} \gamma_{3}\right\}+\delta v_{b}\left(\sigma_{2}-\frac{\hat{\sigma}_{2}^{2}}{\sigma_{2}}\right)=\max \left\{\frac{1}{K} \frac{\hat{\sigma}_{1}}{\sigma_{2}} \gamma_{1}, \frac{\hat{\sigma}_{2}}{\sigma_{2}} \gamma_{3}\right\}+\delta v_{b}\left(\sigma_{2}-\frac{\hat{\sigma}_{2}^{2}}{\sigma_{2}}\right)$,

where $K$ is defined as $\hat{\sigma}_{1}^{2} / \hat{\sigma}_{2}^{2}$.

Because the density of $z=\max \left\{\gamma_{1} / A, \gamma_{3} / B\right\}$ is $A \Phi(B z) \phi(A z)+B \Phi(A z) \phi(B z)$, the probability of promotion for manager 2 is

$$
\begin{aligned}
W_{2}= & \int_{-\infty}^{\infty}\left\{K \frac{\sigma_{2}}{\hat{\sigma}_{1}} \Phi\left(\frac{\sigma_{2}}{\hat{\sigma}_{2}} z\right) \phi\left(K \frac{\sigma_{2}}{\hat{\sigma}_{1}} z\right)+\frac{\sigma_{2}}{\hat{\sigma}_{2}} \Phi\left(K \frac{\sigma_{2}}{\hat{\sigma}_{1}} z\right) \phi\left(\frac{\sigma_{2}}{\hat{\sigma}_{2}} z\right)\right\} \\
& \times\left\{1-\Phi\left(z+\delta v_{b}\left(\sigma_{2}-\frac{\hat{\sigma}_{2}^{2}}{\sigma_{2}}\right)\right)\right\} \mathrm{d} z .
\end{aligned}
$$


Breaking apart the two pieces and applying simple linear transformations produces

$$
\begin{aligned}
W_{2}= & \int_{-\infty}^{\infty} \Phi\left(\frac{\gamma}{\sqrt{K}}\right) \phi(\gamma)\left[1-\Phi\left(\frac{1}{K} \frac{\hat{\sigma}_{1}}{\sigma_{2}} \gamma+\delta v_{b}\left(\sigma_{2}-\frac{\hat{\sigma}_{2}^{2}}{\sigma_{2}}\right)\right)\right] \mathrm{d} \gamma \\
& +\int_{-\infty}^{\infty} \Phi(\sqrt{K} \gamma) \phi(\gamma)\left[1-\Phi\left(\frac{\hat{\sigma}_{2}}{\sigma_{2}} \gamma+\delta v_{b}\left(\sigma_{2}-\frac{\hat{\sigma}_{2}^{2}}{\sigma_{2}}\right)\right)\right] \mathrm{d} \gamma .
\end{aligned}
$$

In the proof of Proposition 8, Lemma 1 shows that the nonrationed managers will choose positive $s$, not $s=0$, so $\sigma_{2}>\sigma_{\theta+u}$. This means that $\partial W_{2} / \partial \sigma_{2}$ must be equal to zero. Equilibrium also requires that $\sigma_{2}=\hat{\sigma}_{2}$, which yields the following condition:

$$
\begin{aligned}
0= & \frac{1}{\hat{\sigma}_{1}} \int_{-\infty}^{\infty} \gamma \Phi\left(\frac{\gamma}{\sqrt{K}}\right) \phi(\gamma) \phi\left(\frac{\gamma}{\sqrt{K}}\right) \mathrm{d} \gamma-2 \delta v_{b} \int_{-\infty}^{\infty} \Phi\left(\frac{\gamma}{\sqrt{K}}\right) \phi(\gamma) \phi\left(\frac{\gamma}{\sqrt{K}}\right) \mathrm{d} \gamma \\
& +\frac{1}{\hat{\sigma}_{2}} \int_{-\infty}^{\infty} \gamma \Phi(\sqrt{K} \gamma)[\phi(\gamma)]^{2} \mathrm{~d} \gamma-2 \delta v_{b} \int_{-\infty}^{\infty} \Phi(\sqrt{K} \gamma)[\phi(\gamma)]^{2} \mathrm{~d} \gamma .
\end{aligned}
$$

Applying (A3)-(A6) produces

$$
\frac{K}{2 \pi(1+K) \sqrt{2+K} \hat{\sigma}_{1}}-\frac{\delta v_{b} \sqrt{K}}{\sqrt{2 \pi} \sqrt{1+K}}+\frac{\sqrt{K}}{4 \pi \sqrt{2+K} \sigma_{2}}-\frac{\delta v_{b}}{2 \sqrt{\pi}}=0 .
$$

Recall that $K=\hat{\sigma}_{1}^{2} / \hat{\sigma}_{2}^{2}$.

In the case where manager 1 adds no variance, $\hat{\sigma}_{1}=\sigma_{\theta+u}$ and $\sigma_{2}=\sigma_{\theta+u} / \sqrt{K}$ can be substituted into (B6). This substitution and some algebra gives Equation (16), the implicit definition of $K$ in Part 1 of Proposition 7. $K \geq 0$ is required for the left-hand side of (16) to be real, and the proof of Lemma 1 shows that (16) requires $K<1$. Tedious calculations show that there exists a unique $K$ that satisfies (16), with $0<K<1$, so Part 1 of the proposition is proved.

In the case where manager 1 does add variance, we must determine the optimal choice $\sigma_{1}$ and that, together with (B6), will characterize the equilibrium with differential capital allocations.

\section{The rationed manager}

Manager 1 faces two rivals who behave identically. Using the same logic as in the previous subsection, manager 1 wins promotion if

$$
\left(\frac{\sigma_{\theta}^{2}}{\hat{\sigma}_{1}^{2}}\right) \sigma_{1} \gamma_{1}-\delta v_{a} \sigma_{\theta}^{2}\left(\frac{\sigma_{1}^{2}}{\hat{\sigma}_{1}^{2}}-1\right)>\frac{\sigma_{\theta}^{2}}{\hat{\sigma}_{2}} \gamma_{2} \quad \text { and } \quad\left(\frac{\sigma_{\theta}^{2}}{\hat{\sigma}_{1}^{2}}\right) \sigma_{1} \gamma_{1}-\delta v_{a} \sigma_{\theta}^{2}\left(\frac{\sigma_{1}^{2}}{\hat{\sigma}_{1}^{2}}-1\right)>\frac{\sigma_{\theta}^{2}}{\hat{\sigma}_{2}} \gamma_{3} \text {, }
$$

that is, if

$$
\gamma_{1}>\left(\frac{\hat{\sigma}_{1}^{2}}{\hat{\sigma}_{2}^{2}}\right)\left(\frac{\hat{\sigma}_{2}}{\sigma_{1}}\right) \max \left\{\gamma_{2}, \gamma_{3}\right\}+\delta v_{a}\left(\sigma_{1}-\frac{\hat{\sigma}_{1}^{2}}{\sigma_{1}}\right)=K \frac{\hat{\sigma}_{2}}{\sigma_{1}} \max \left\{\gamma_{2}, \gamma_{3}\right\}+\delta v_{a}\left(\sigma_{1}-\frac{\hat{\sigma}_{1}^{2}}{\sigma_{1}}\right) .
$$

Because the density of $z=\max \left\{\gamma_{2}, \gamma_{3}\right\}$ is $2 \Phi(z) \phi(z)$, the probability of promotion for manager 1 is

$$
W_{1}=2 \int_{-\infty}^{\infty} \Phi(z) \phi(z)\left\{1-\Phi\left(K \frac{\hat{\sigma}_{2}}{\sigma_{1}} z+\delta v_{a}\left(\sigma_{1}-\frac{\hat{\sigma}_{1}^{2}}{\sigma_{1}}\right)\right)\right\} \mathrm{d} z
$$


If $v_{a}$ is large enough, manager 1 maximizes $W_{1}$ by adding no variance: $s_{1}^{2}=0$ so $\sigma_{1}^{2}=\sigma_{\theta+u}^{2}$. If $v_{a}$ is not so large, the optimal $\sigma_{1}$ is found by differentiating $W_{1}$ with respect to $\sigma_{1}$ :

$$
\frac{\partial W_{1}}{\partial \sigma_{1}}=2 \int_{-\infty}^{\infty} \Phi(z) \phi(z) \phi\left(K \frac{\hat{\sigma}_{2}}{\sigma_{1}} z+\delta v_{a}\left(\sigma_{1}-\frac{\hat{\sigma}_{1}^{2}}{\sigma_{1}}\right)\right)\left[\frac{\hat{\sigma}_{2}}{\sigma_{1}^{2}} K z-\delta v_{a}\left(1+\frac{\hat{\sigma}_{1}^{2}}{\sigma_{1}^{2}}\right)\right] \mathrm{d} z=0 .
$$

In equilibrium, the owner's expectations are fulfilled, so this simplifies to

$$
\int_{-\infty}^{\infty} \Phi(z) \phi(z) \phi(\sqrt{K} z)\left(\frac{\sqrt{K}}{\hat{\sigma}_{1}} z-2 \delta v_{a}\right) \mathrm{d} z=0 .
$$

Applying (A1) and (A2), this further simplifies to

$$
\frac{\sqrt{K}}{2 \pi(1+K) \sqrt{2+K} \hat{\sigma}_{1}}-\frac{\delta v_{a}}{\sqrt{2 \pi(1+K)}}=0 \quad \Longrightarrow \quad \delta v_{a} \sqrt{2 \pi(1+K)(2+K)} \hat{\sigma}_{1}=\sqrt{K} .
$$

This gives the expression for $\sigma_{1}$ in Part 2 of Proposition 7. To get (17), the equation defining $K$ in Part 2 of the proposition, substitute $\sigma_{2}=\hat{\sigma}_{1} / \sqrt{K}$ in (B6), then use (B7) to substitute for $\hat{\sigma}_{1}$ in (B6), and then rearrange. We must have $K \geq 0$ for the left-hand side of (17) to be real. One can verify (see the proof of Proposition 8) that the left-hand side is increasing in $K$, is negative at $K=0$, and is positive for large $K$, so it has a unique solution. This proves Proposition 7.

Proof of Proposition 8: We begin with a lemma that shows that the nonrationed managers add some risk, so $\sigma_{2}>\sigma_{\theta+u}$. Therefore, proving the lemma establishes the proposition for the case where $\sigma_{1}=\sigma_{\theta+u}$. For the case where $\sigma_{1}>\sigma_{\theta+u}$, we then prove that $\sigma_{2}$ is even larger than $\sigma_{1}$.

Lemma 1. Assume that (15) holds and that only division 1 is rationed. Then, the nonrationed managers add risk in equilibrium: $\sigma_{2}>\sigma_{\theta+u}$.

Proof of lemma: To reach a contradiction, suppose the equilibrium has $\hat{\sigma}_{2}=\sigma_{\theta+u}$, which implies $K \equiv \hat{\sigma}_{1}^{2} / \hat{\sigma}_{2}^{2} \geq 1$. For this corner solution to be optimal for the nonrationed managers, it would have to be true that $\partial W_{2} / \partial \sigma_{2} \leq 0$ when evaluated at $\sigma_{2}=\sigma_{\theta+u}$. Using the left-hand side of (B6) and substituting $\sqrt{K} \sigma_{2}$ for $\hat{\sigma}_{1}$,

$$
\left.\frac{\partial W_{2}}{\partial \sigma_{2}}\right|_{\sigma_{2}=\sigma_{\theta+u}} \leq 0 \Longleftrightarrow \delta v_{b} \sigma_{\theta+u} \geq \frac{\sqrt{K}(K+3)}{2 \sqrt{\pi(2+K)(1+K)}(\sqrt{2 K}+\sqrt{1+K})} .
$$

For $K \geq 1$, this expression is decreasing in $K$ to a limit of $1 /[2(1+\sqrt{2}) \sqrt{\pi}]$. This being so, the inequality implies that $\delta v_{b} \sigma_{\theta+u}$ is greater than $1 /[2(1+\sqrt{2}) \sqrt{\pi}]$, which contradicts (15). Therefore, one cannot have $\sigma_{2}=\sigma_{\theta+u}$ in equilibrium, and the lemma is proved.

It remains to prove that when $\sigma_{1}$ is larger than $\sigma_{\theta+u}, \sigma_{2}$ is larger still. For this case, (B6) and (B7) jointly determine the equilibrium strategies. Combining these two equations yields the equilibrium condition (17), which we write as $T(K)=0$, with

$$
T(K) \equiv \sqrt{K}(3+K)-(2 \sqrt{K}+\sqrt{2(1+K)}) \frac{v_{b}}{v_{a}} .
$$

$T$ is an increasing function, as $T^{\prime}(K)$ has the same sign as

$$
\begin{aligned}
& \left(\frac{3}{2 \sqrt{K}}+\frac{3 \sqrt{K}}{2}\right)(2 \sqrt{K}+\sqrt{2+2 K})-(3 \sqrt{K}+K \sqrt{K})\left(\frac{1}{\sqrt{K}}+\frac{1}{\sqrt{2+2 K}}\right) \\
& =2 K+\frac{3 \sqrt{2+2 K}}{2 \sqrt{K}}+\frac{2 K \sqrt{K}}{\sqrt{2+2 K}}>0 .
\end{aligned}
$$


Since $T(0)=-\sqrt{2} v_{b} / v_{a}<0$ and $T(1)=4\left(1-\left(v_{b} / v_{a}\right)\right)>0$, this establishes that there is a unique $K$ satisfying $T(K)=0$ and this solution has $K \in(0,1)$.

Proof of Proposition 9: By Proposition 8, the nonrationed managers add strictly more risk than the rationed manager, i.e., $\sigma_{1}<\sigma_{2}=\sigma_{3}$ in equilibrium. Based on the owner's Bayesian updating, the posterior mean $\bar{\theta}_{1 i}$ has a normal distribution with mean zero and standard deviation $\sigma_{\theta}^{2} / \sigma_{i}$. This implies that the probability that manager 1 is promoted is

$$
2 \int_{-\infty}^{\infty} \Phi(z) \phi(z)\left\{1-\Phi\left(\frac{\sigma_{1}}{\sigma_{2}} z\right)\right\} \mathrm{d} z=2 \int_{-\infty}^{\infty} \Phi(z) \phi(z)[1-\Phi(\sqrt{K} z)] \mathrm{d} z
$$

By integrating separately over $\{z<0\}$ and $\{z>0\}$ and using the transformation $y=-z$ for negative $z$, this promotion probability can be written as

$$
\begin{aligned}
2 \int_{0}^{\infty} \Phi(z) \phi(z)[1-\Phi(\sqrt{K} z)] d z+2 \int_{0}^{\infty} \Phi(\sqrt{K} z) \phi(z)[1-\Phi(z)] \mathrm{d} z \\
=2 \int_{0}^{\infty} \Phi(z) \phi(z)[1-\Phi(z)] d z+2 \int_{0}^{\infty} \Phi(z) \phi(z)[\Phi(z)-\Phi(\sqrt{K} z)] \mathrm{d} z \\
\quad-2 \int_{0}^{\infty}[\Phi(z)-\Phi(\sqrt{K} z)] \phi(z)[1-\Phi(z)] \mathrm{d} z+2 \int_{0}^{\infty} \Phi(z) \phi(z)[1-\Phi(z)] \mathrm{d} z \\
=4 \int_{0}^{\infty} \Phi(z) \phi(z)[1-\Phi(z)] d z+2 \int_{0}^{\infty}[\Phi(z)-\Phi(\sqrt{K} z)] \phi(z)\{\Phi(z)-[1-\Phi(z)]\} \mathrm{d} z \\
=\frac{1}{3}+2 \int_{0}^{\infty}[\Phi(z)-\Phi(\sqrt{K} z)] \phi(z)\{\Phi(z)-[1-\Phi(z)]\} \mathrm{d} z .
\end{aligned}
$$

Each factor in the remaining integral is positive, as $z>0$ and $\sqrt{K}<1$. This proves that the rationed manager's promotion probability is greater than $1 / 3$, and the probabilities for the nonrationed managers are less than $1 / 3$.

\section{References}

Antle, R., and G. D. Eppen. 1985. Capital Rationing and Organizational Slack in Capital Budgeting. Management Science 31:163-74.

Aron, D. J., and E. P. Lazear. 1987. Competition, Relativism, and Market Choice. Discussion Paper \#750, Northwestern University, Center for Mathematical Studies in Economics and Management Science.

Bognanno, M. 2001. Corporate Tournaments. Journal of Labor Economics 19:290-315.

Bolton, P., J. Scheinkman, and W. Xiong. 2006. Executive Compensation and Short-Termist Behavior in Speculative Markets. Review of Economic Studies 73:577-610.

Cadenillas, A., J. Cvitanic, and F. Zapatero. 2005. Optimal Risk-Sharing with Effort and Project Choice. Working Paper, University of Alberta.

Craig, S., and R. Smith. 2004. Morgan Stanley Ousts President Amid Shake-Up. The Wall Street Journal, March $29, \mathrm{C} 1$.

Flint, J. 2004. Viacom Seals Deal for One, Maybe Two, CEOs After Redstone. The Wall Street Journal, July 23, A9.

Gitman, L., and J. Forrester. 1977. A Survey of Capital Budgeting Techniques Used by U.S. Firms. Financial Management 6:66-71.

Green, J. R., and N. L. Stokey. 1983. A Comparison of Tournaments and Contracts. Journal of Political Economy 91:349-64. 
Grossman, S. J., and O. D. Hart. 1986. The Costs and Benefits of Ownership: A Theory of Vertical and Lateral Integration. Journal of Political Economy 94:691-719.

Harris, M., and A. Raviv. 1996. The Capital Budgeting Process, Incentives and Information. Journal of Finance 51:1139-74.

Hart, O., and J. Moore. 1990. Property Rights and the Nature of the Firm. Journal of Political Economy 98:111958.

Hirshleifer, D., and Y. Suh. 1992. Risk, Managerial Effort, and Project Choice. Journal of Financial Intermediation 3:308-45.

Holmström, B., and J. Ricart i Costa. 1986. Managerial Incentives and Capital Management. Quarterly Journal of Economics 101:835-60.

Jensen, M. C. 1986. Agency Costs of Free Cash Flow, Corporate Finance, and Takeovers. American Economic Review 76:323-29.

Lambert, R., D. Larcker, and K. Weigelt. 1993. The Structure of Organizational Incentives. Administrative Science Quarterly 38:438-61.

Lazear, E. P., and S. Rosen. 1981. Rank-Order Tournaments as Optimum Labor Contracts. Journal of Political Economy 89:841-64.

MacLeod, W. B., and J. M. Malcolmson. 1988. Reputation and Hierarchy in Dynamic Models of Employment. Journal of Political Economy 96:832-54.

Milbourn, T. T., R. L. Shockley, and A. V. Thakor. 1999. Prestige, Intrafirm Tournaments, and Failure Aversion in Corporate Decisions. Working Paper No. 99-003, Washington University, Olin School of Business, St. Louis.

Mukherjee, T. K., and V. L. Hingorani. 1999. Capital-Rationing Decisions of Fortune 500 Firms: A Survey. Financial Practice and Education 9:7-15.

Rajan, R. G., H. Servaes, and L. Zingales. 2000. The Cost of Diversity: The Diversification Discount and Inefficient Investment. Journal of Finance 55:35-80.

Rosen, S. 1986. Prizes and Incentives in Elimination Tournaments. American Economic Review 76:701-16.

Scharfstein, D. S., and J. C. Stein. 2000. The Dark Side of Internal Capital Markets: Divisional Rent-Seeking and Inefficient Investment. Journal of Finance 55:2537-64.

Stein, J. C. 1997. Internal Capital Markets and the Competition for Corporate Resources. Journal of Finance 52:111-34.

Stein, J. C. 2002. Information Production and Capital Allocation: Decentralized versus Hierarchical Firms. Journal of Finance 57:1891-922.

Thakor, A. V. 1990. Investment "Myopia" and the Internal Organization of Capital Allocation Decisions. Journal of Law, Economics, and Organization 6:129-54. 